\title{
أثر السياسات الزراعية على محصول فول الصويا فى مصر
}

\section{منال مشهور السيد}

باحث- معهد بحوث الصحراء

الملخص : يتتاول البحث قياس أثر السياسات الزراعية على محصول فول الصويا فى مصر خلال الفترة

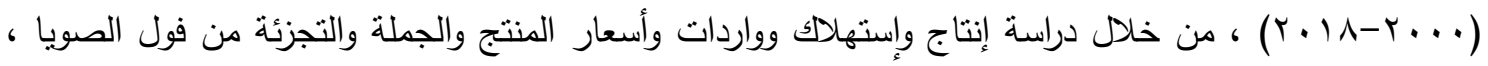
قياس مصفوفة تحليل السياسات لمحصول فول الصويا .

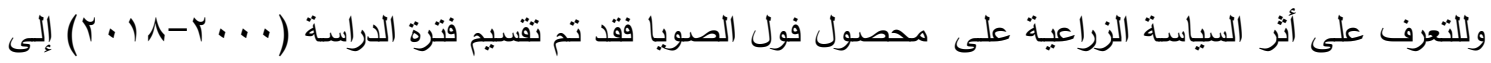

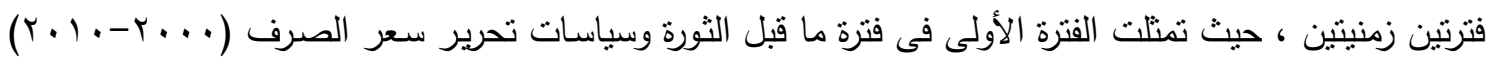

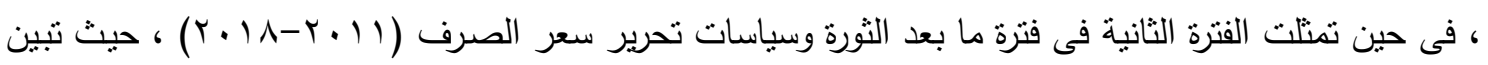

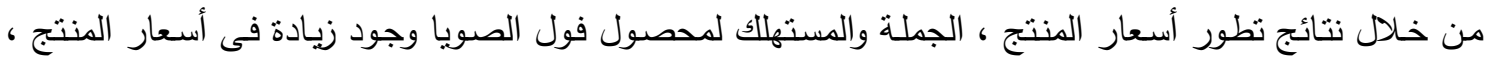

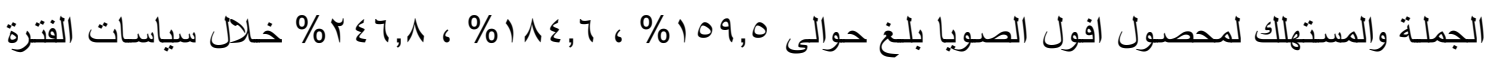
الثانية عن الفترة الأولى من الدراسة. كما تبين من خلال نتائج قياس أثر السياسات الزراعية على أهم العوامل المرتبطة بالأمن الغذائى لدحصول فول

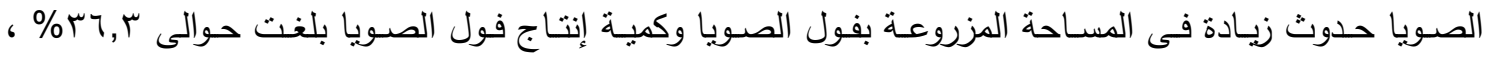
\& \&, >

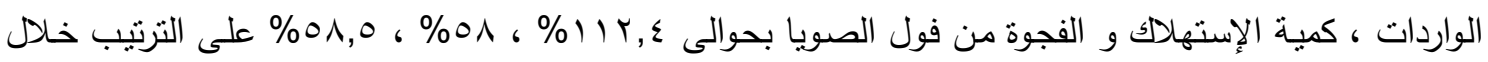

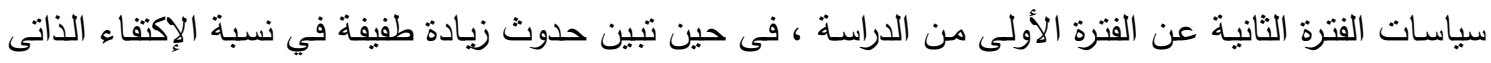

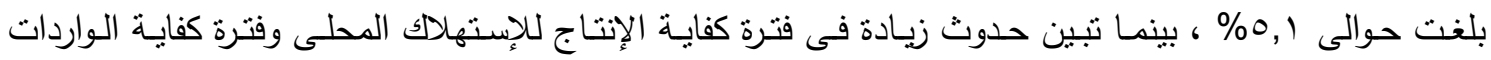

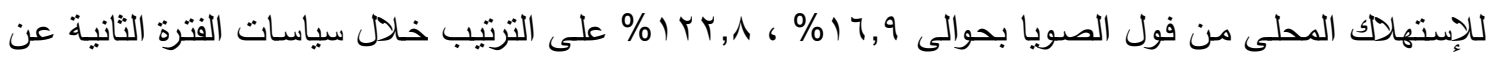

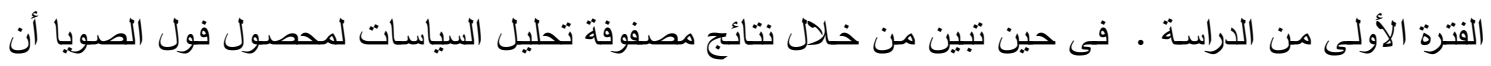

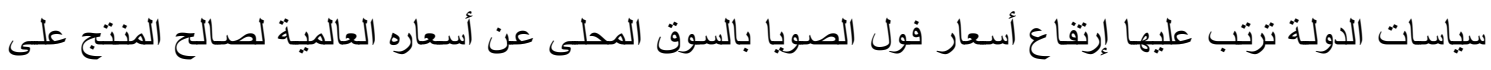

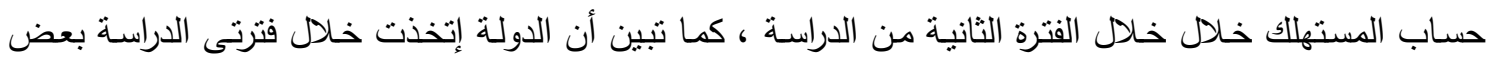

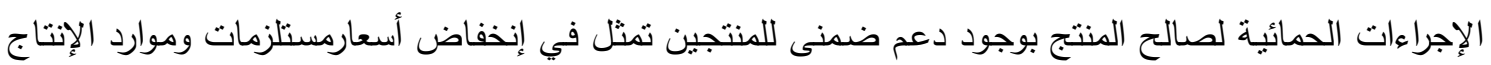

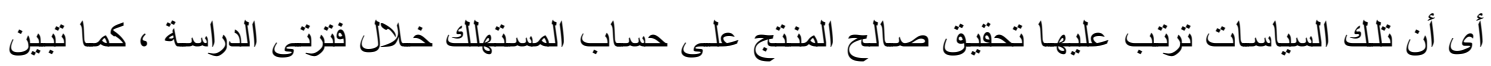

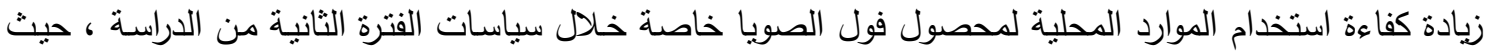

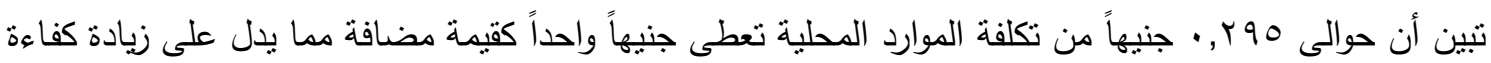
استخدام الموارد المحلية خلال سياسات تلاك الفنترة.

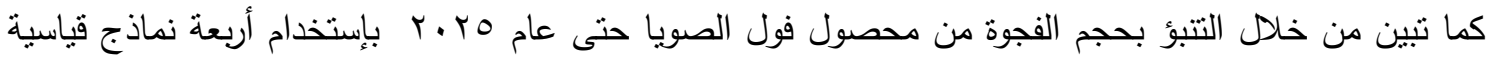

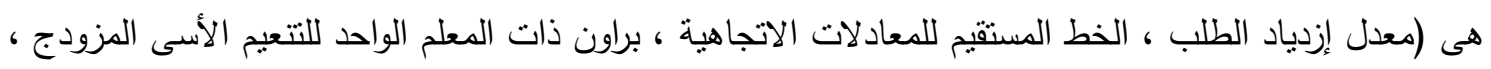

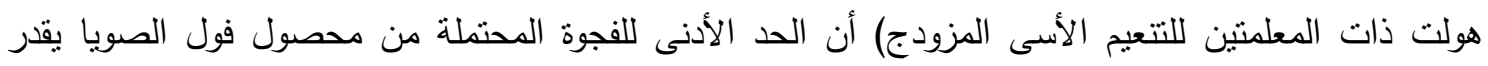

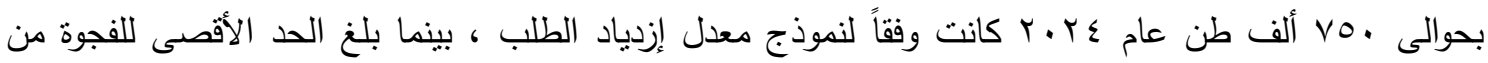




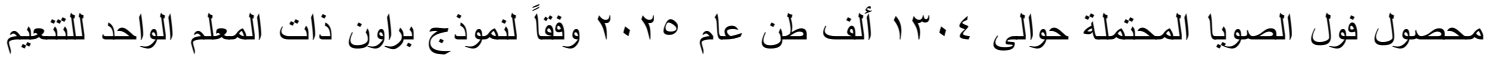
الأسى المزدوج. وقد توصل البحث إلى مجموعة من التوصبات التى تقيد صانعى القرار فى السياسة الاقتصادية الزراعية قي هذا المجال.

الكلمات المفتاحية: انتاج واستهلاك فول الصويا - مصفوفة تحليل السياسات الزراعية - نموذج التوازن الجزئي نماذج التنبؤ.

\section{مقدمة}

تعتبر مشكلة نقص الغذاء وتحقيق الإكتفاء الذاتى لسلع الأمن الغذائى من أهم المشاكل الرئيسية فى مصر والعالم ،

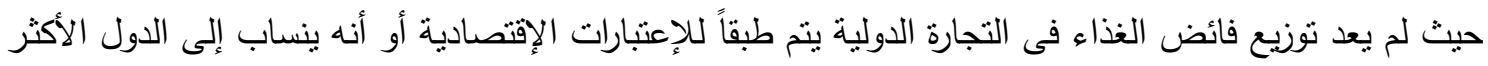

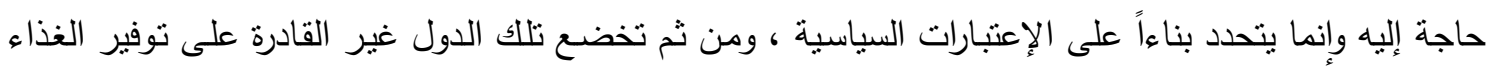

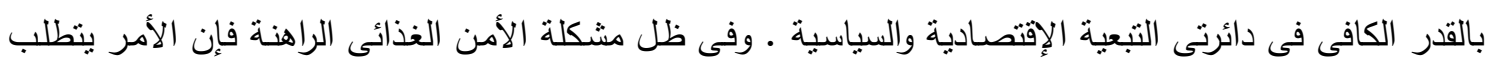

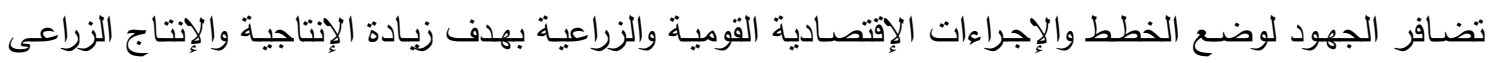

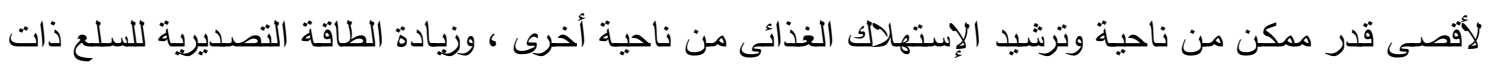

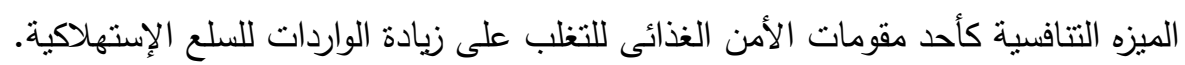

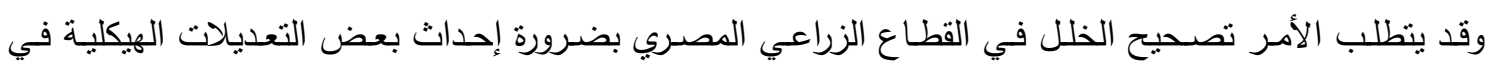

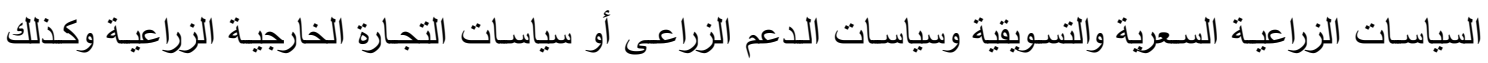

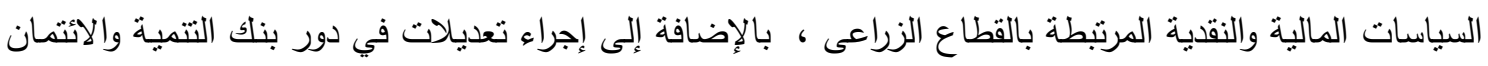

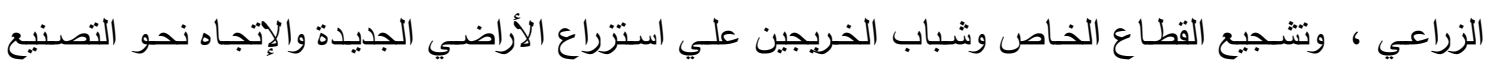

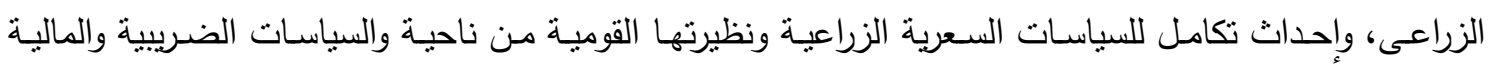
والنقدية والائتمانية وسياسات الدخل والأجور والتجارة الخارجية الزراعية من ناحية أخري ـ وفى ظل تحرير أسعار المحاصيل الزراعية وتركها لقوي العرض والطلب ، وتقليص دور الدولة في تحديد المساحات المحصولية والإكتفاء

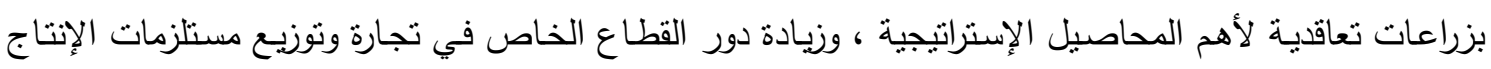

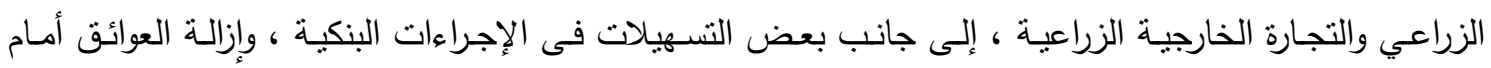

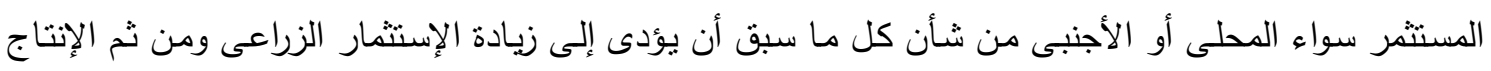

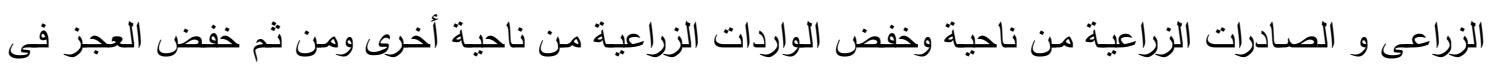
الميزان التجارى الكلى والزراعى المصرى.

المشكلة البحثية

يعتبر فول الصويا من أهم المحاصيل الزيتية فى مصر و يمثل حوالى بr, • \% من إجمالى المساحة المزروعة

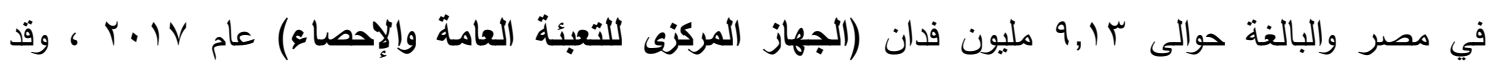

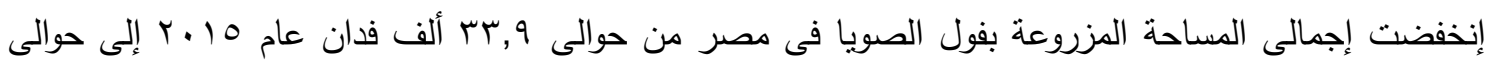

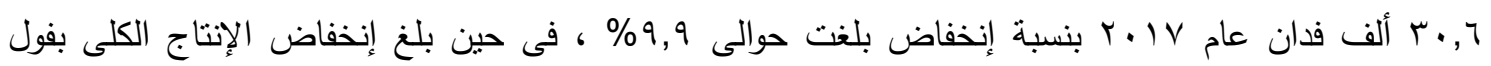
الصويا من حوالى V, Y

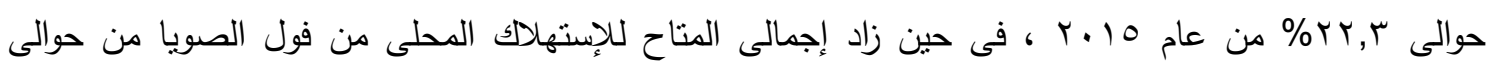

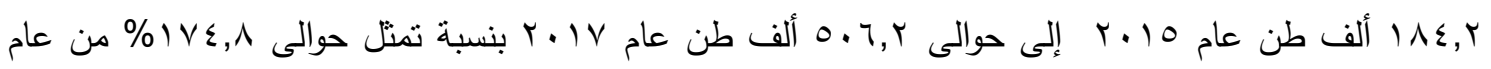




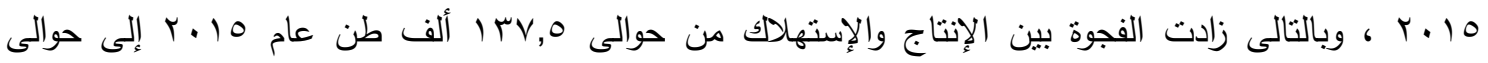

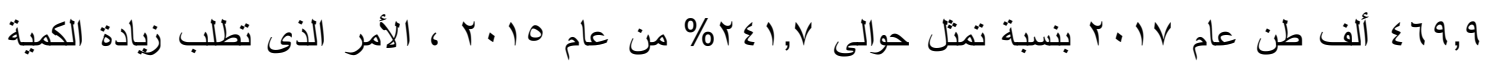

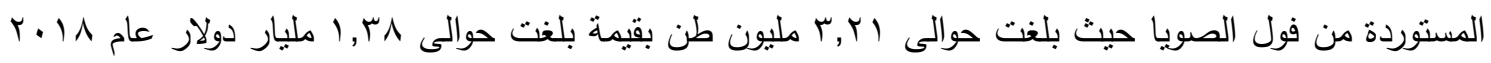

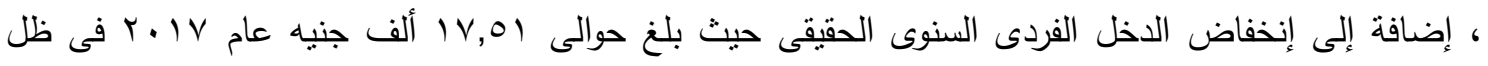

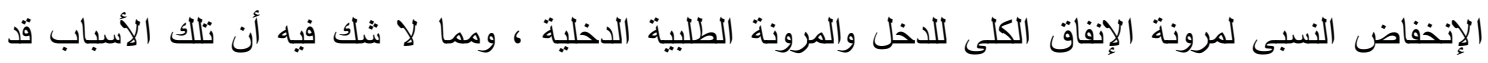

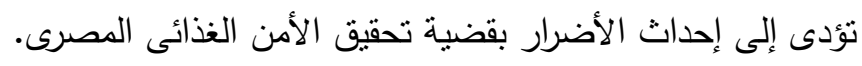
وقد إعتمدت السياسة الإقتصادية الزراعية المصرية على تحقيق عدة أهداف منها زيادة سعر الفائدة ليصل لسعر لئر

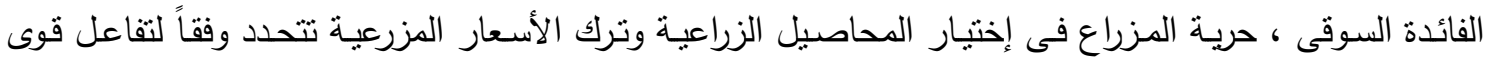
العرض والطلب، تحرير تجارة مستلزمات الإتتاج الزراعى، تخفيف القيود على التجارة الخارجية الزراعية ، تحرير سعر صرف الدولار مقابل الجنيه المصرى ، ولاثك أن كل تلك السياسات قد تؤدى لحدوث تغييرات إقتصـادية بالقطاع الزراعى من شأنها تحقيق زيادة فى الإكتفاء الذاتى من السلع الزراعية الغذائية وخاصـة الإستراتيجية ، الإِ

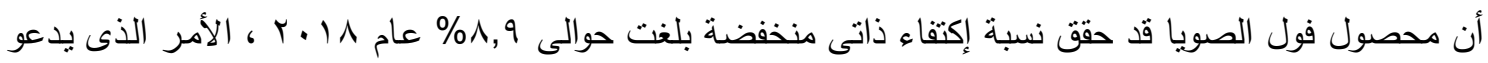

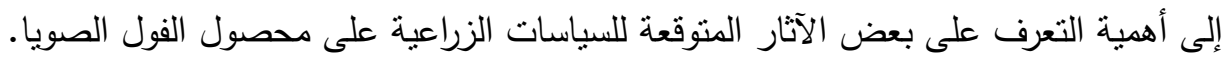

الأهداف البحثية

يستهدف هذا البحث قياس أثر السياسات الزراعية على محصول فول الصويا فى مصر من خلال دراسة تطور :

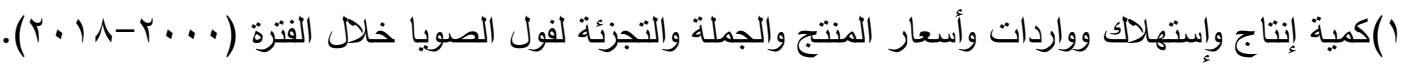

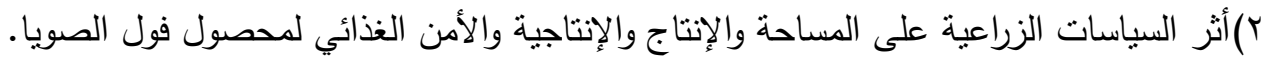

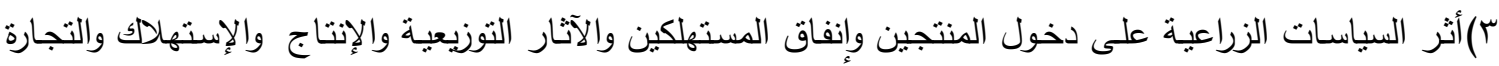

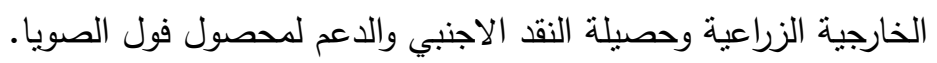

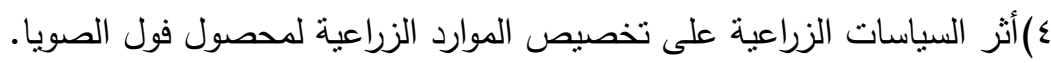
×حساب الهوامش التسويقية والكفاءة النسويقية لمحصول فول الصويا. ؟)التقدير القياسى لدالة الطلب الإستهلاكى ودالة الواردات الخارجية من فول الصويا.

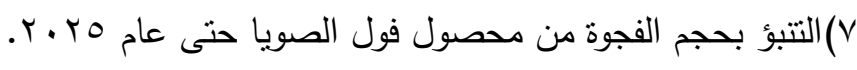
الإسلوب البحثى ومصادر البيانات تم إستخدام إسلوب تحليل بيانات السلاسل الزمنية المتعلقة بإنتاج وإستهلاك وصادرات وواردات وأسعار محصول فول الصويا بإستخدام أدوات التحليل الإحصائى الإقتصادى الوصفى والإستدلالى ونماذج تحليل الإنحدار البسيط والمتعدد لدراسة أثر السياسات الزراعية على محصول فول الصويا (الرسول ويسيونى، 991 (19)، كما تم إستخدام نموذج التوازن الجزئى لإستكثاف أثز السياسة الزراعية على كل من الإنتاج والإنتاجية والإستهلاك والمتغيرات

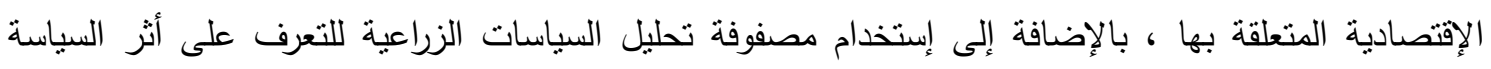

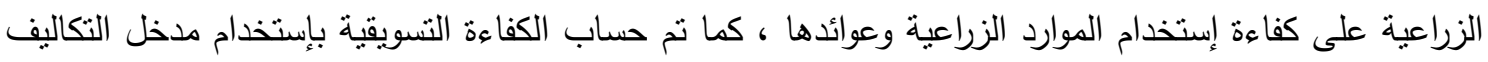
التسويقية، كما تم إستخدام نماذج (معدل إزدياد الطلب ، الخط المستقيم للمعادلات الاتجاهية ، براون ذاته الماته المعلم

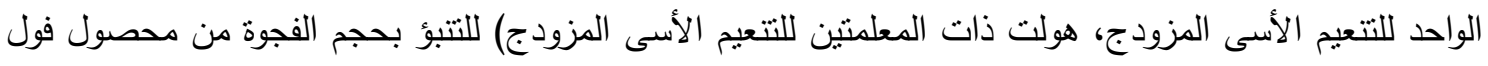
الصويا .وقد اعتمد البحث على البيانات الثانوية المنشورة في العديد من الجهات الرسمية منل وزارة الزراعة 
وإستصلاح الأراضي، والنشرات الصادرة من الجهاز المركزي للتعبئة العامة والإحصاء، وإحصاءات خريطة التجارة

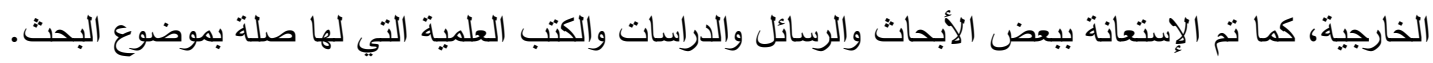

\section{النتائج البحثية وإلمناقثة}

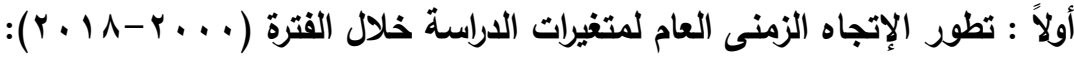

تبين من خـلال دراسة تطور المساحة المزروعة بمحصول فول الصويا أنها زادت من حوالى ؟, 9, ألف طن عام

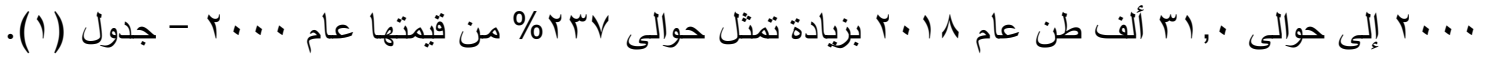

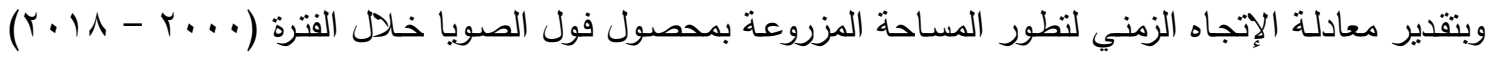

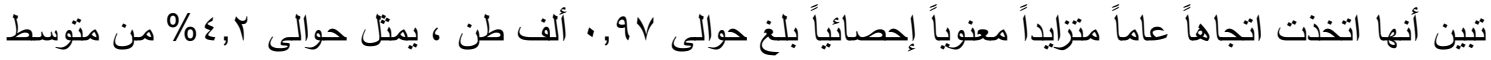

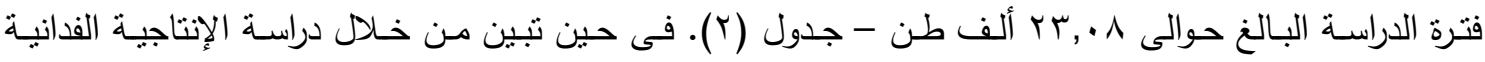

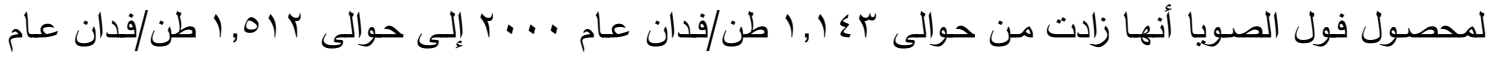

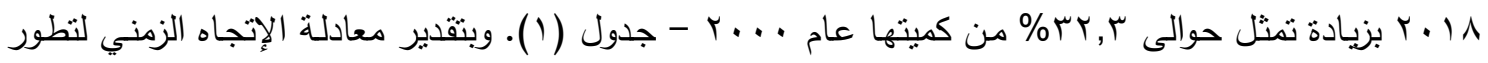
الإنتاجية الفدانية لمحصول فول الصويا خلال فترة الدراسة تبين أنها اتخذت اتجاهاً عاماً متزايداً معنوياً إحصائباً

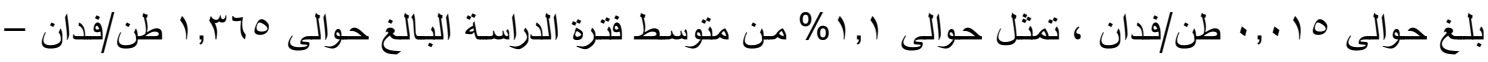
جدول (r).

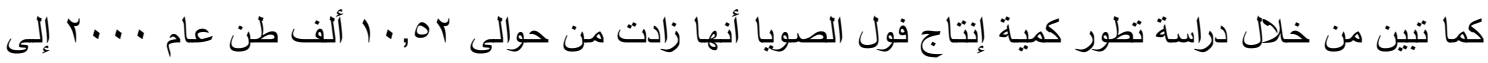

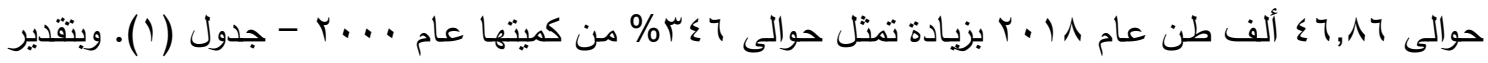

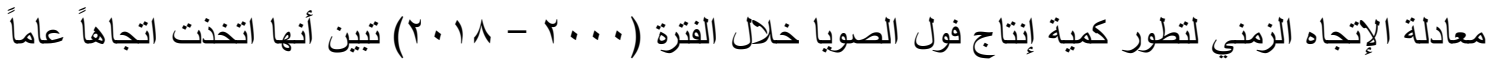

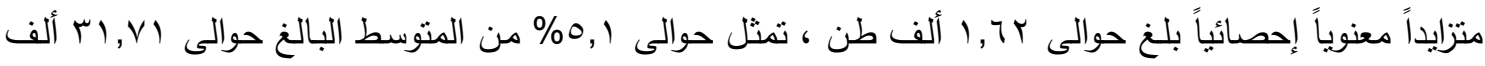

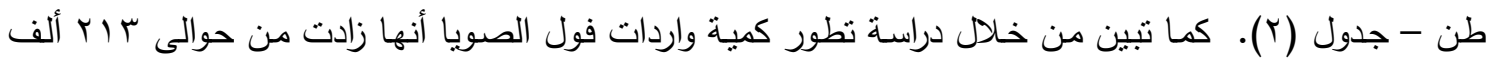

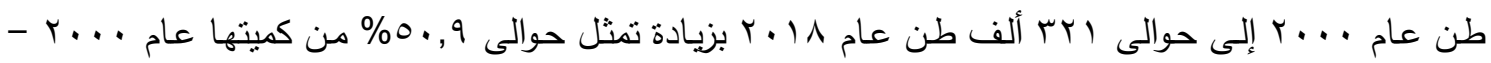

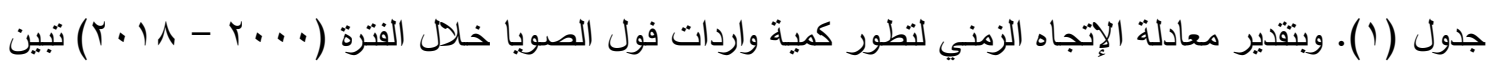

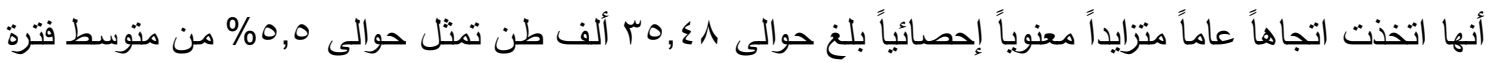

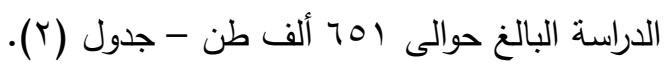

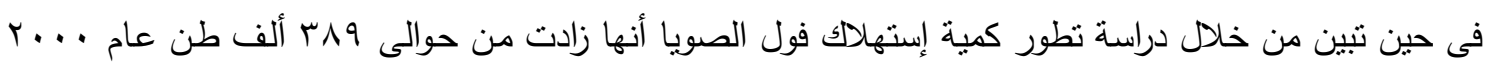

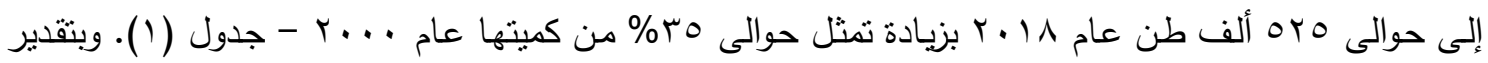

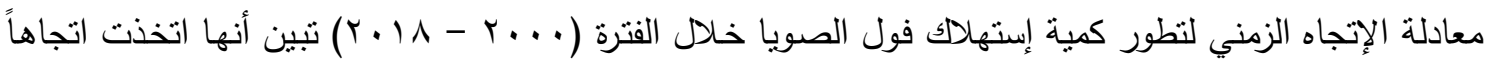

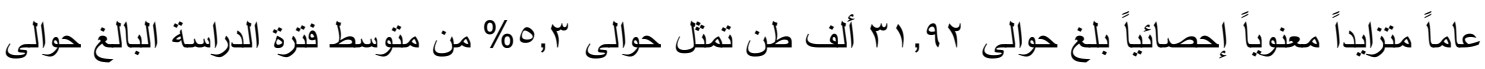

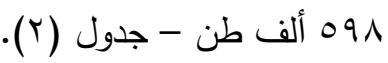

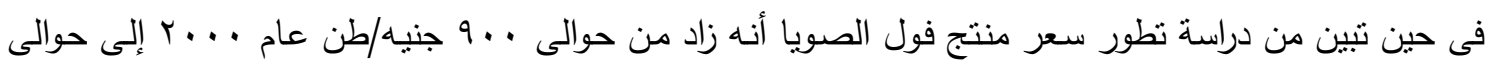

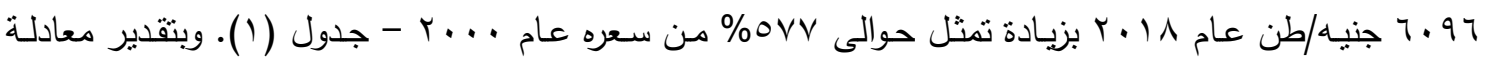

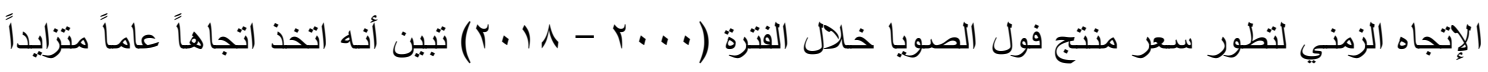

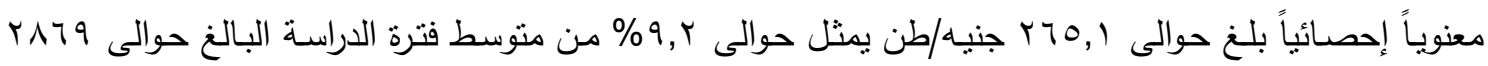

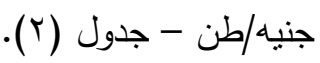

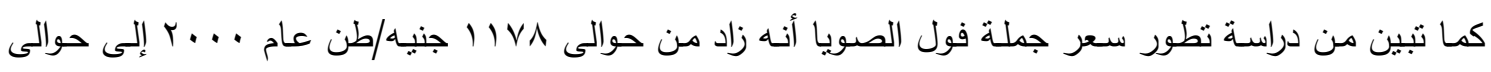

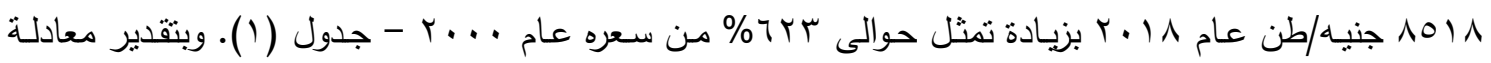


الإتجاه الزمني لنطور سعر جملة فول الصويا خلال فترة الدراسة تبين أنه اتخذ اتجاهاً عاماً متزايداً معنوياً إحصائباً

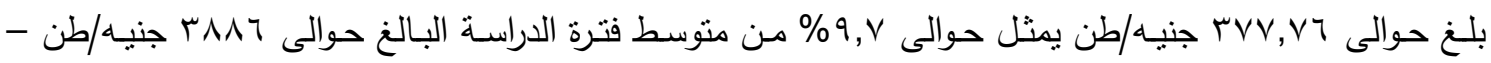

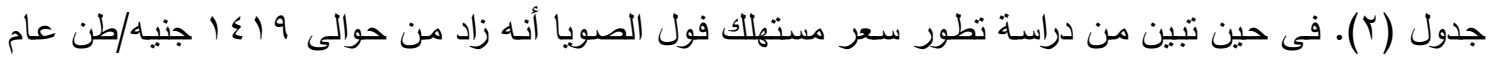

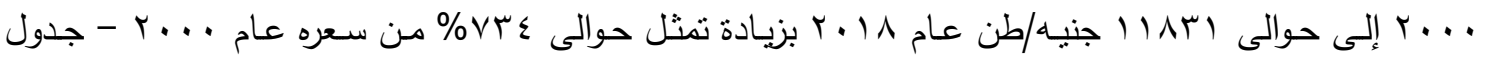
(1). وبتقدير معادلة الإتجاه الزمني لنطور سعر مستهلك فول الصويا خلال فترة الدراسة تبين أنه اتخذ اتجاهاً عاماً

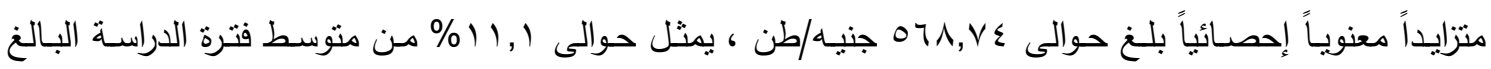

حوالى بr r إه جنيه/طن - جدول (r).

ثانياً:أثر السياسات الزراعية على أهم العوامل المرتبطة بالأمن الغذائى لمحصول فول الصويا:

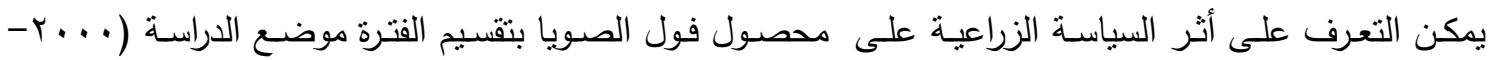

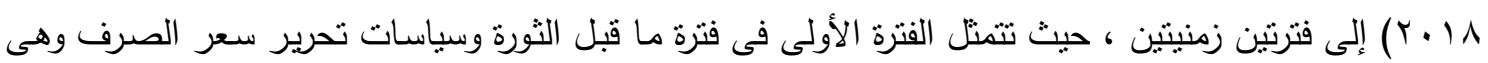

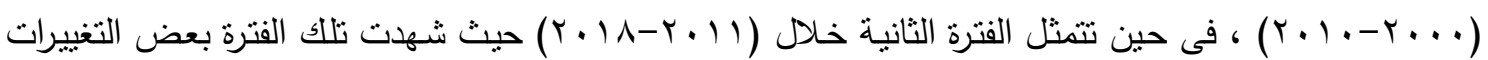

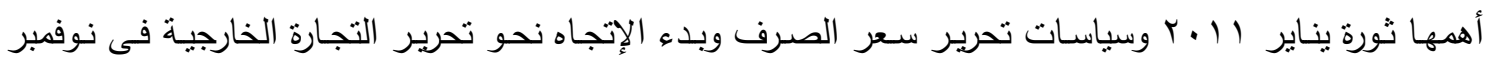
7 ا ـ ب ، وذلك بهذف تحليل أثز تلك السياسات على محصول فول الصويا.

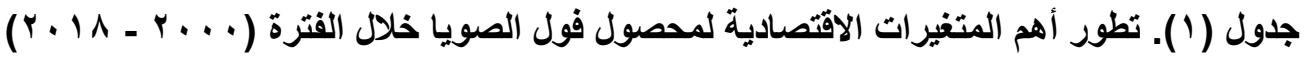

\begin{tabular}{|c|c|c|c|c|c|c|c|c|}
\hline ستر المستهلكاك) & سنر الجملة & سنر المنتج) & المتاح للإستهلاك & كمية الواردات & (الالفت طن) & الإنتاجية & (ألف فـانة) & السنة \\
\hline $1 \leqslant 19$ & $11 V A$ & $9 \ldots$ & rᄉq & rIr & $1 \cdot, 0 r$ & $1,1 \leqslant r$ & $q, r$. & $r \ldots$ \\
\hline $1 \leq \leqslant 9$ & 1119 & $9 \ldots$ & r7o & ro. & $1 \varepsilon, \wedge 9$ & אי & 15,79 & $r \ldots 1$ \\
\hline $194 \varepsilon$ & $10 \% 0$ & 110. & $r \varepsilon$. & Tr & 18,79 & 1, ror & $1 \varepsilon, 1$ & $r \ldots r$ \\
\hline ro19 & TYTY & 1770 & 171 & ITr & $r \wedge, 7 \wedge$ & 1, & $19, V \leq$ & $r \ldots r$ \\
\hline rAIT & $r \leqslant 70$ & 111. & rod & rio & $\varepsilon r, \varepsilon r$ & $1, r V T$ & $r \varepsilon, 10$ & $r \ldots \varepsilon$ \\
\hline rTlo & גשrז & 1101 & $7 .$. & ov & ro,, 1 & $1, Y \wedge T$ & $r \cdot, \cdot \Lambda$ & $r \ldots o$ \\
\hline rovs & TrYE & 19.1 & 097 & ovr & ru, & $1, r q \leq$ & $1 \vee \vee \vee 9$ & $r \ldots r$ \\
\hline rqए & roqv & 1904 & 1174 & דrr & ro,, 71 & i,ritr & $11,0 \leq$ & $r \ldots v$ \\
\hline סטדr & rqo & YITI & Mוג & $\varepsilon \cdot r$ & rq,iv & $1, \leqslant 11$ & $r \cdot, T V$ & $r \ldots \Lambda$ \\
\hline rquv & $r \leq \Lambda \leq$ & $r T \cdot V$ & orv & $\varepsilon \leqslant 0$ & $r \tau, \varepsilon$. & $1,0 \leq 1$ & $1 V, \cdot 7$ & $r \ldots q$ \\
\hline T. 9 & rา 99 & דודי & OrY & $\varepsilon q \vee$ & & 1,190 & אז,ד'r & $r .1$. \\
\hline$O V \cdot r$ & $\varepsilon r V \varepsilon$ & & 1109 & 1117 & $r q, V V$ & . ו, ו. & YY,VY & $r .11$ \\
\hline Vrug & 07.1 & $\varepsilon \| V$ & $|r| \mid$ & iror & ro, $9 \leq$ & 1,017 & $\mid v, 11$ & $r \cdot 1 r$ \\
\hline$V \vee \ldots$ & OVTV & 纟rl. & אדצו & $1 \cdot 1$. & rY, Vo & $1, \leqslant 7$. & $r Y, \leqslant r$ & $r+1 r$ \\
\hline$\Lambda \leq \vee\urcorner$ & О人тA & $\{r T \mid$ & roq & $1 \leqslant 1$. & $r q, \wedge \tau$ & $1,19 q$ & $r \wedge, \leqslant q$ & $r .1 \leq$ \\
\hline A9ाV & סחודי & דזrع & $1 \Lambda \varepsilon$ & $1 T \leqslant 7$ & $\leq 7,7 V$ & I,rVV & . & r. 10 \\
\hline$q \cdot v V$ & 7107 & $\varepsilon \Gamma \wedge \wedge$ & 1.9 & $\varepsilon r$. & $\leq 0,1 \leq$ & $1, \varepsilon \cdot 1$ & $r, .0$ & $r .17$ \\
\hline 1.771 & $V \leq 77$ & سoror & 0.7 & $\{71$ & $\varepsilon V^{\prime}, \cdot V$ & $1,0 \leq$. & $r \cdot, 07$ & $r+1 r$ \\
\hline |11 & 1011 & 7.97 & oro & Tr & $\leq 7, \wedge\rceil$ & $1,01 Y$ & ו, . & $r+1 \Lambda$ \\
\hline $01 Y 7$ & 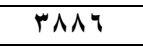 & ห^\q & 091 & 701 & $r 1, v 1$ & 1,470 & $r r, \cdot \Lambda$ & المتوسط \\
\hline rol $\varepsilon$ & Y) & 1817 & $\leqslant \wedge 1$ & $\varepsilon \leqslant r$ & $r T, r$ & $1, r)$ & $r \cdot, \cdot r$ & 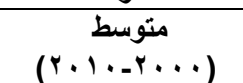 \\
\hline AVIV & מצT & $\varepsilon \varepsilon$ or & VT. & $9+1$ & $r q, r$ & $1, \varepsilon \leqslant$. & $r V, r \wedge$ & $\begin{array}{c}\text { متوسط } \\
(Y \cdot \mid \Lambda-Y \text {. II) }\end{array}$ \\
\hline$T H \cdot T$ & $\varepsilon . r q$ & TVTV & rVq & $\varepsilon 9 V$ & $1 \pi$ & $\cdot, 1 \mu$ & $V, r$ & أثر التغير بين الفترتين \\
\hline$r \leqslant 7, \wedge$ & $1 \wedge \varepsilon, 7$ & 109,0 & $0 \wedge$, & $M r, \varepsilon$ & $\varepsilon 9, V$ & 9,9 & r4,r & نسبة الأثر \\
\hline
\end{tabular}

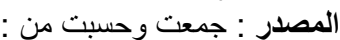

ا ـالجهاز المركزى للتعبئة العامة وحند الإحصاء ، نشرة حركة الإنتاج والتجارة الخارجية والمتاح للإستهلاك من السلع الزراعية ، أعداد منقرقة. r- الموقع الإلكترونى للجهاز المركزى للتعبئة العامة والإحصاء: 
جـول (Y). معسـلات الإتجـاه الزمنـى العسام لتطـور إنتـاج وإسـتهلاك وواردات وأسـعار فـول الصـويا خـلال

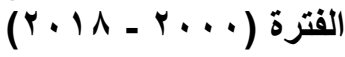

\begin{tabular}{|c|c|c|c|c|c|}
\hline $\mathbf{F}$ & $\mathbf{R}^{2}$ & معدل النمو & المتوسط السنوى & النموذج & | المتغير \\
\hline $14.4^{\star *}$ & 0.458 & 4.2 & 23.08 & $\begin{array}{c}\hat{\mathbf{Y}}_{\mathrm{t}}=13.38++0.97 \mathrm{~T} \\
(3.79)^{* *}\end{array}$ & (ألف فداحة) \\
\hline $14.0^{* *}$ & 0.452 & 1.1 & 1.365 & $\begin{array}{c}\hat{\mathbf{Y}}_{\mathrm{t}}=1.216+0.015 \mathrm{~T} \\
(3.74)^{* *}\end{array}$ & (طن/فالانية) \\
\hline $29.6^{\star *}$ & 0.636 & 5.1 & 31.71 & $\begin{array}{c}\hat{\mathrm{Y}}_{\mathrm{t}}=15.47+1.62 \mathrm{~T} \\
(5.44)^{\star \star}\end{array}$ & كمية الإنتاج \\
\hline $4.6^{*}$ & 0.213 & 5.5 & 650.8 & $\begin{array}{c}\hat{\mathrm{Y}}_{\mathrm{t}}=296.0+35.48 \mathrm{~T} \\
(2.14)^{*}\end{array}$ & كمية الإستهلاك طن \\
\hline $5.2^{*}$ & 0.234 & 5.3 & 598.1 & $\begin{array}{c}\hat{\mathrm{Y}}_{\mathrm{t}}=321.0+31.92 \mathrm{~T} \\
(2.28)^{*}\end{array}$ & كمية الواردات \\
\hline $195.2^{* *}$ & 0.920 & 9.2 & 2868.7 & $\begin{array}{c}\hat{\mathrm{Y}}_{\mathrm{t}}=217.8+265.1 \mathrm{~T} \\
(13.97)^{* *}\end{array}$ & سعر المنتج) \\
\hline $151.9^{* *}$ & 0.899 & 9.7 & 3886.4 & $\begin{array}{c}\hat{\mathbf{Y}}_{\mathrm{t}}=108.7+377.8 \mathrm{~T} \\
(12.33)^{* *}\end{array}$ & سعز الجملة \\
\hline $132.4^{* *}$ & 0.886 & 11.1 & 5125.6 & $\begin{array}{c}\hat{\mathbf{Y}}_{\mathrm{t}}=561.9+568.7 \mathrm{~T} \\
(11.51)^{* *}\end{array}$ & سنر المستهلكاطن) \\
\hline
\end{tabular}

المصدر : جمعت وحسبت من جدول (1) (1) (1)

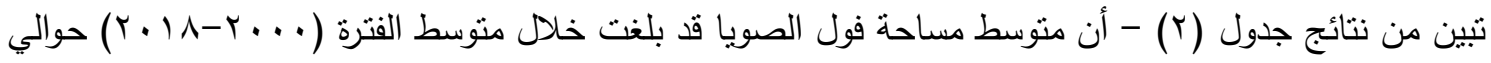

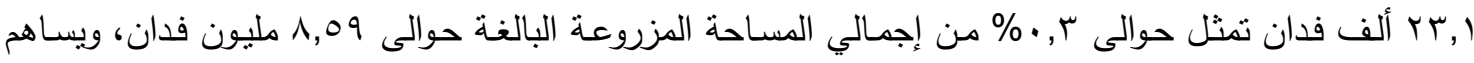

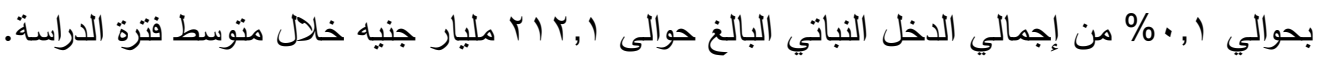

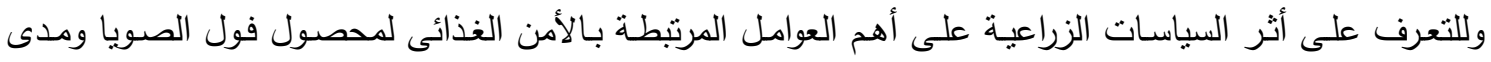

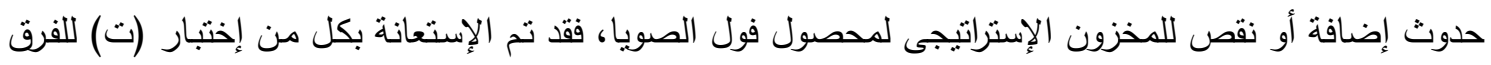

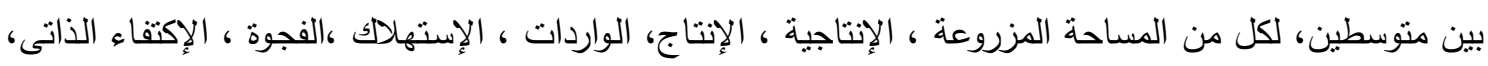

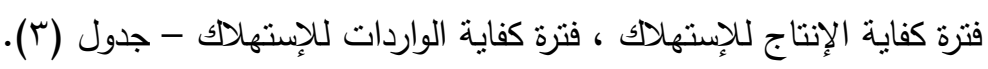

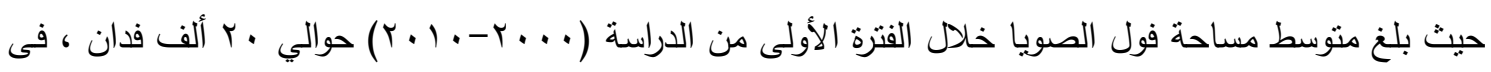

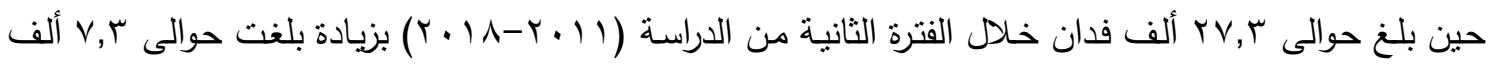
فدان تمثل حوالي ؟, ؟ب\% عن الفترة الأولى ، وهذا يعتبر مؤثراً فى صالح السياسة الإقتصادية ، كما تبين وفقاً لإختبار (t) وجود فروق معنوية إحصائياً بين متوسط الفترتين عند مستوى إحتمالى ه ه. ., ..

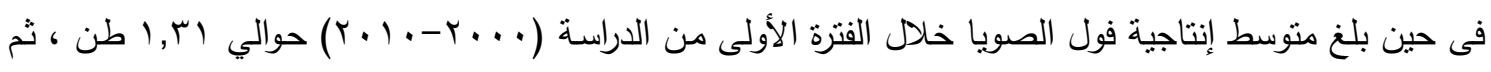

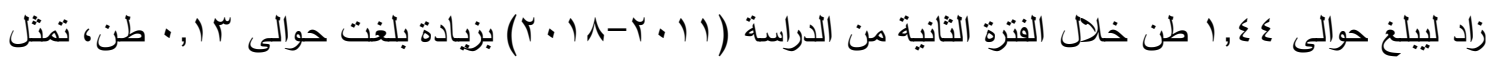

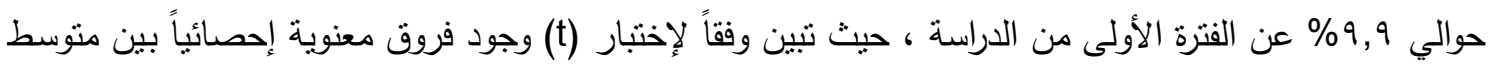

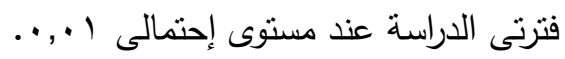

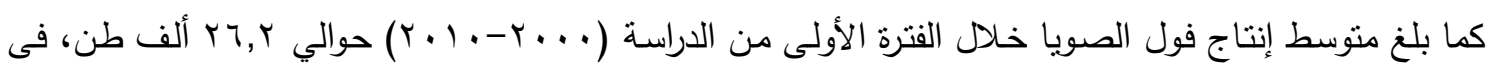

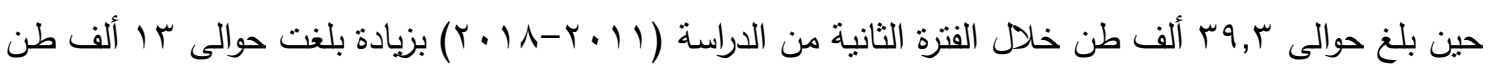

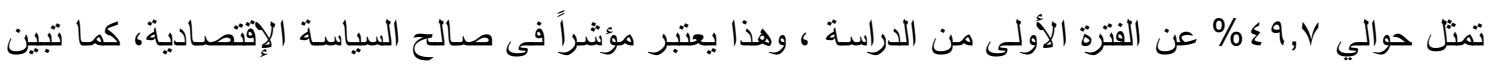
وفقاً لإختبار (t) وجود فروق معنوية إحصائياً بين منوسط فترتى الدراسة عند مستوى إحتمالى ل ا.,... 
فى حين أوضحت النتائج أن كمية الواردات من فول الصويا قد إزدادت من حوالى بـ ؟ ألف طن كمتوسط للفترة

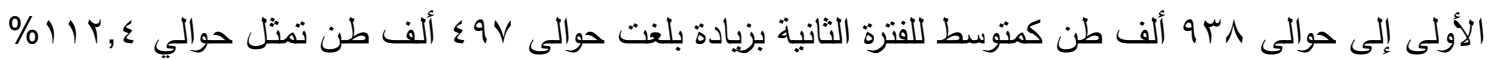

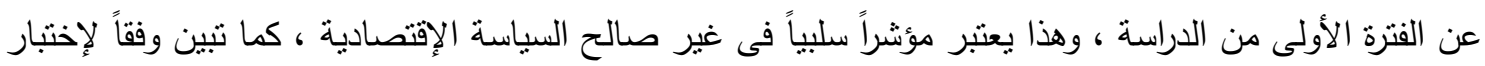

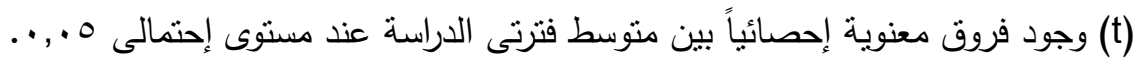

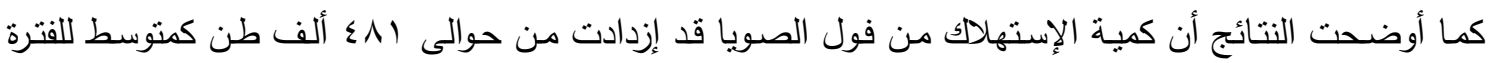

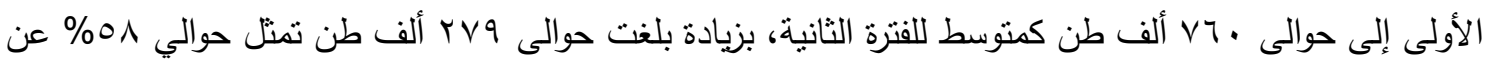
الفترة الأولى من الدراسة ، كما تبين وفقاً لإختبار (t) وجود فروق غير معنوية إحصائياً بين متوسط فترتى الدراسية

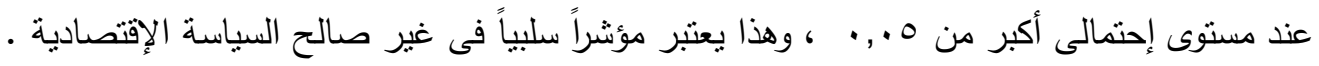

كما تبين من النتائج أن الفجوة بين الإنتاج المحلى للفول الصويا والإستهلاك المحلى منه قد إزدادت من حوالى

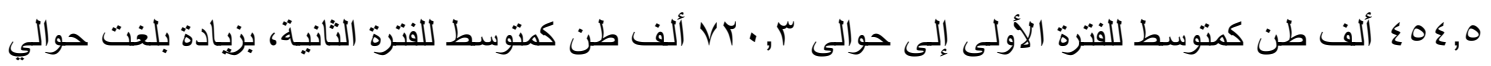

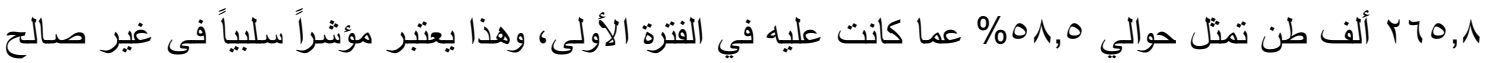

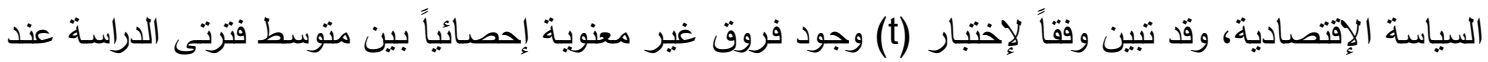
مستوى إحتمالى أكبر من 0 ., ..

وفى ظل إستخدام سياسة زراعية تستهدف تحقيق أسعار مجزية للمزارعين مما يؤدى الى زيادة المساحة المزروعة

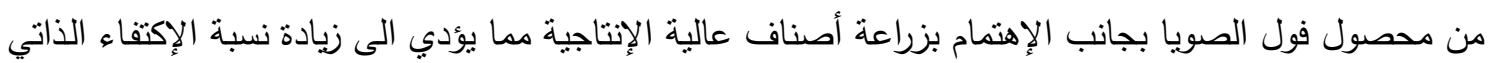

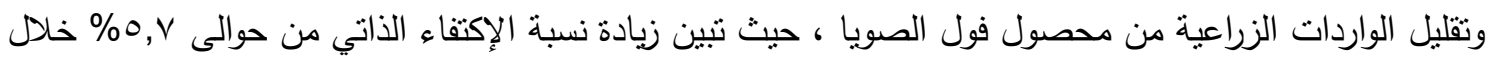

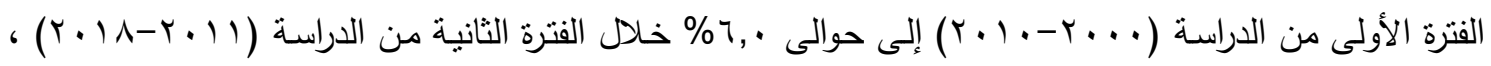

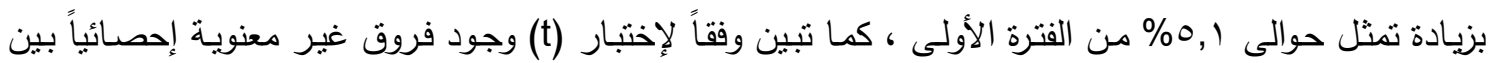

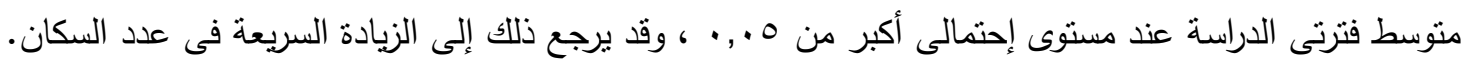

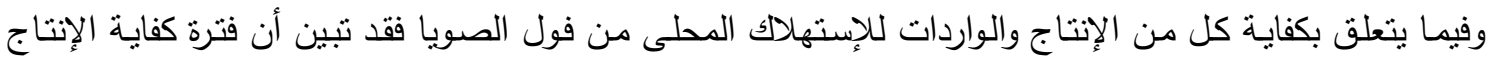

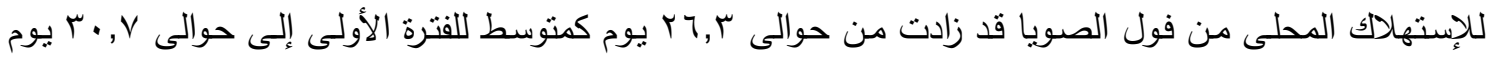

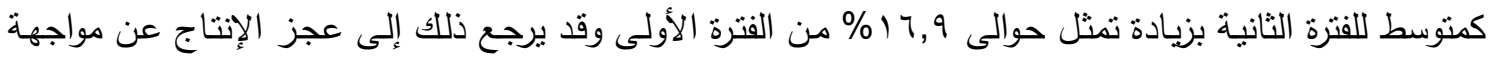

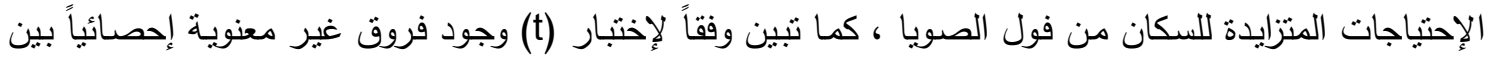

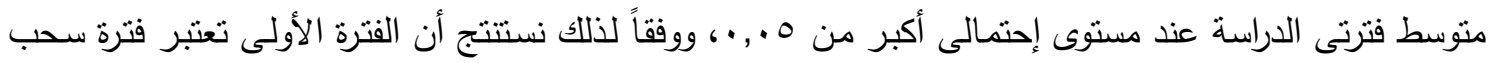

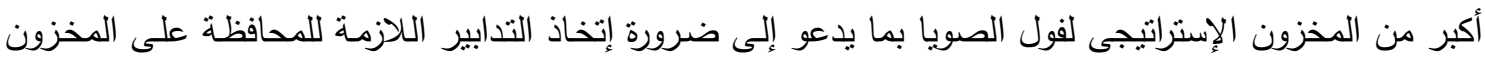
وتتميته ، ووضع سياسات مرتبطة بزيادة إنتاج وخفض إستيراد فول الصويا.

فى حين تبين تزايد فترة كفاية الواردات للإستهلاك المحلى من حوالى اسب يوم كمنوسط للفترة الأولى إلى حوالى

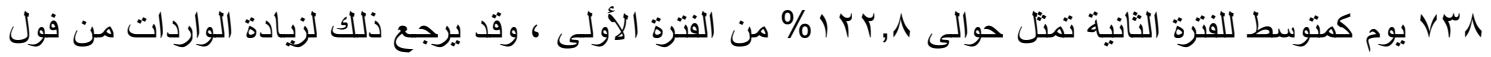
الصويا خلال الفترة الثانية ، كما تبين وفقاً لإختبار (t) وجود فروق غير معنوية إحصائياً بين منوسط فترتى الدراسة كنة عند مسنوى إحتمالى أكبر من 0 ., . . 
جدول رقم (r). نتائج إختبار (t) للفرق بين متوسطين لأهم العوامل المرتبطة بالأمن الغذائى من فول الصويا

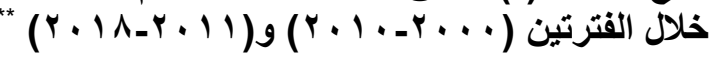

\begin{tabular}{|c|c|c|c|c|c|}
\hline قيمة (ت) للفرق & الفتوسطين بين & متوسط الفترة الثاتية & 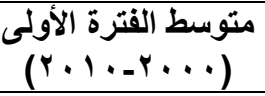 & 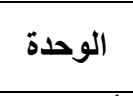 & المتغيـــر \\
\hline$-r, r)^{*}$ & $v, r$ & $r V, r$ & $r \cdot, \cdot$ & ألف فدان & المستاحة \\
\hline$-r, V \wedge^{* *}$ & • & $1, \leqslant \varepsilon$ & $1, r_{1}$ & طن & الإنتاجية القدانية \\
\hline$-r, \cdot 0^{* *}$ & ir, & $r q, r$ & $r 7, r$ & ألف طن & الإنتاج المحلى \\
\hline$-r, V r^{*}$ & $\sum 9 \vee$ & 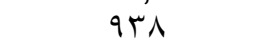 & $\varepsilon \varepsilon r$ & ألف طن & الواردات \\
\hline$-1,70$ & rVq & V.. & 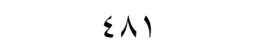 & ألف طن & الإستهلاك المحلى \\
\hline$-1,00$ & $r 70, \wedge$ & $V Y \cdot, r$ & $\leqslant 0 \leqslant, 0$ & ألف طن & الفجوة \\
\hline$-\cdot, \mu \wedge$ & $\cdot r$ & 7, & $0, V$ & $\%$ & نسبة الإكتفاء الذاتى \\
\hline$-\cdot, r q$ & $\varepsilon, \varepsilon$ & $r \cdot, V$ & $r \uparrow, r$ & يوم & فترة كفاية الإنتاج للإستهلاك \\
\hline$-1, r$ & $\varepsilon \cdot v$ & VTr & וTr & يوم & فترة كفاية الواردات للإستتهلاك \\
\hline
\end{tabular}

المصدر : جمعت وحسبت من بيانات جدول (1).

ثالثاً : مصفوفة تحليل السياسـات الزراعيـة لمحصول فول الصـويا (الرسـول ويسيوني 1991 19. ، عبد الرحيم

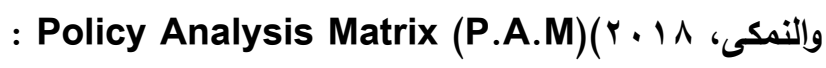

(1) معامل الحماية الأسمية للإنتاج من محصول فول الصويا: تعكس قيمة هذا المعامل حجم الدعم الضمنى أى الحماية للمنتج المحلى أو حجم الضرائب الضمنية الضمنية التي يتحملها

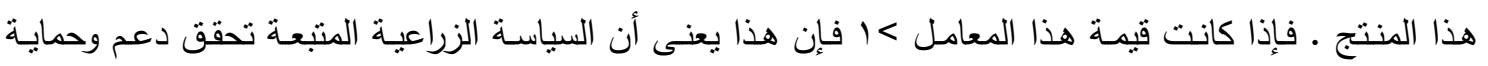

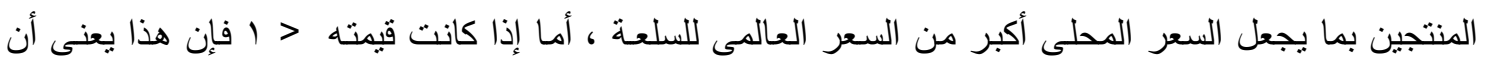

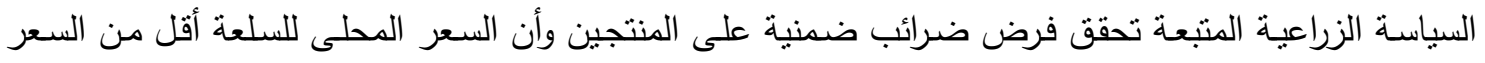

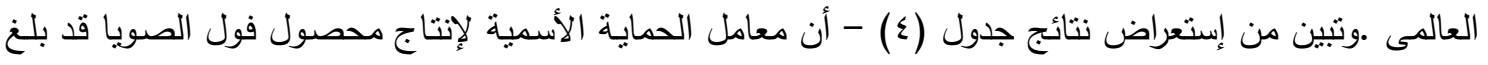

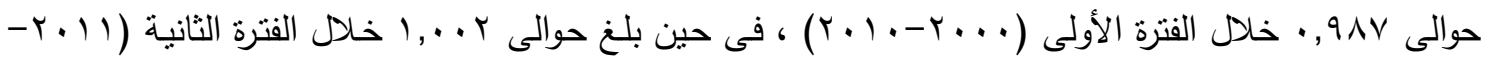

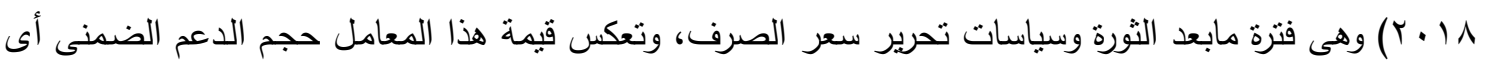

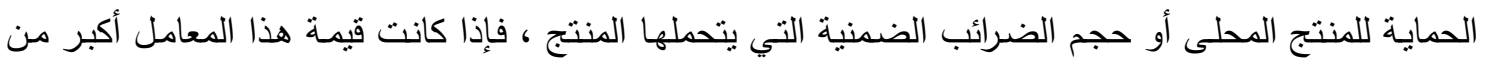

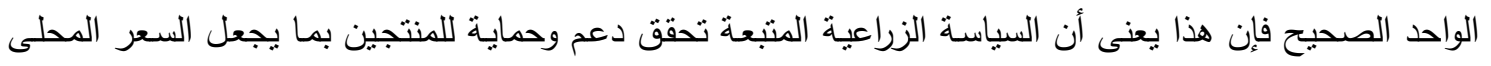

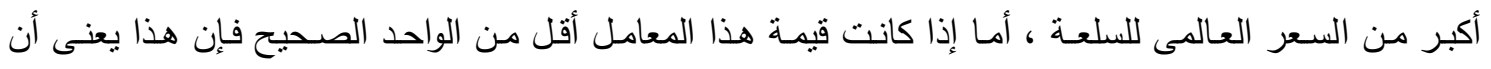

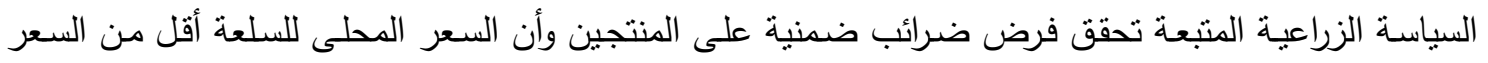

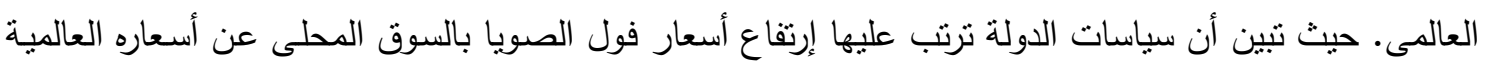
لصالح المنتج على حساب المستهلك خلال الفترة الثانية من الدراسة.

(Y) معامل الحماية الأسمية لمستلزمات إنتاج محصول فول الصويا:

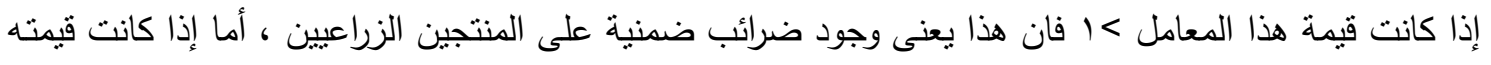

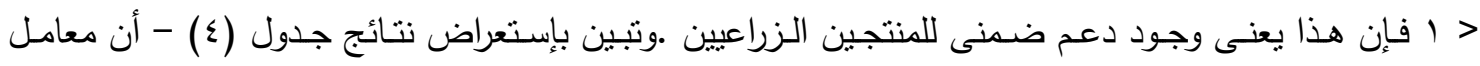

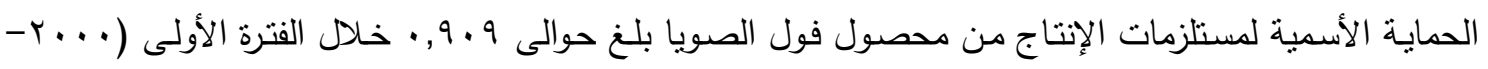

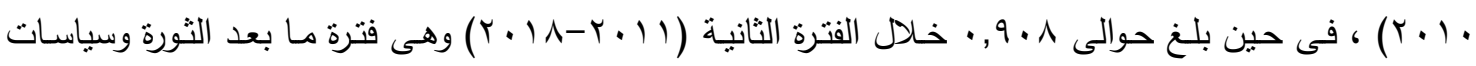
تحرير سعر الصرف. وتعكس قيمة هذا المعامل حجم الضرائب أو الدعم الضمنى ، فإذا كانت قيمة هذا المعامل 
أكبر من الواحد الصحيح فإن هذا يعنى وجود ضرائب ضمنية على المنتجين الزراعيين ، أما إذا كانت قيمة هذا

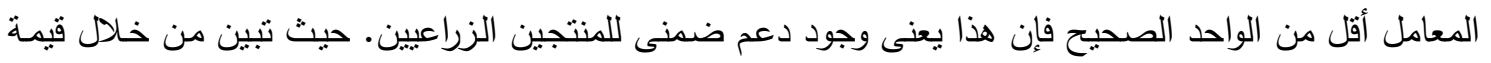

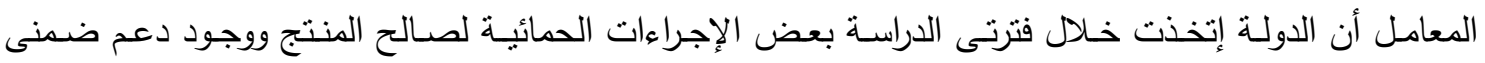
للمنتجين الزراعيين تمثل في إنخفاض أسعارمستلزمات وموارد الإنتاج.

(r) معامل الحماية الفعال لمحصول فول الصويا: تفسير هذا المعامل هو نفس تفسير معامل الحماية الأسمية للإنتاج إلا أنه يأخذ تكاليف المدخلات التجارية في

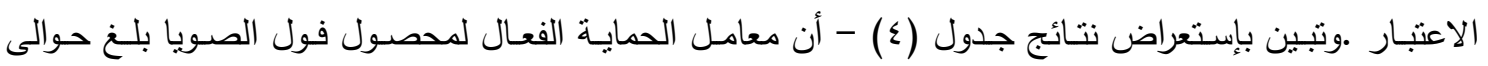

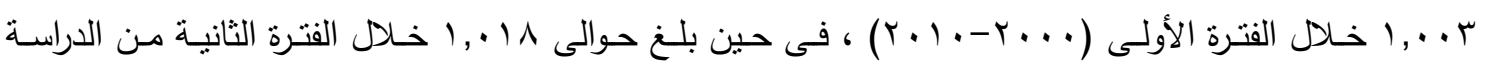

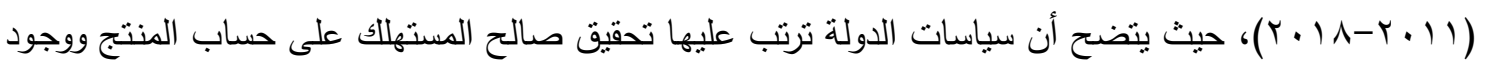
ضرائب ضمنية على المنتجين خلال فترتى الدراسة ، وخاصة خلال الفترة الثانية أى ما بعد الثورة وسياسات تحرير سعر الصرف.

( ) معامل الميزة النسبية الطبيعية فى ظل سياسة التدخل الحكومى: إذا كانت قيمة هذا المعامل > 1 فإن ذلك يعنى عدم كفاءة استخدام الموارد الطبيعية المتاحة في إنتاج سلعة معينة

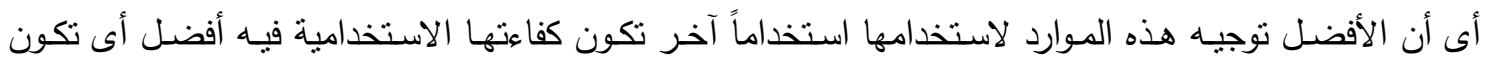

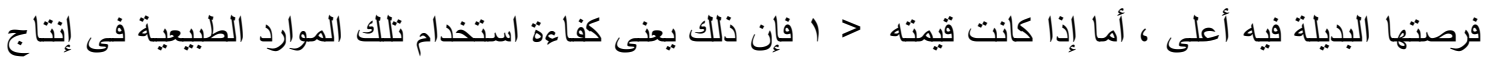

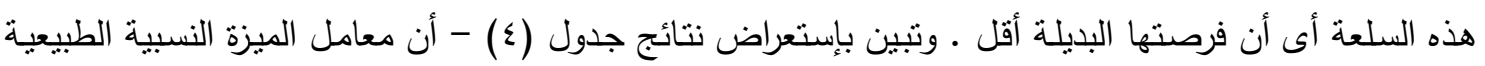

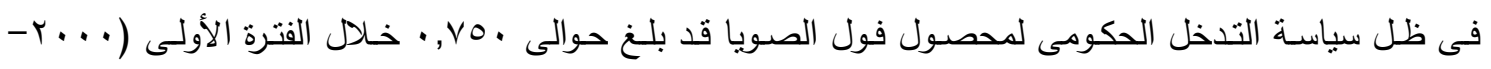

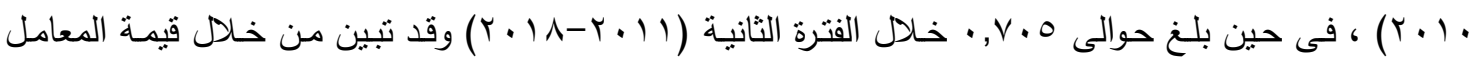

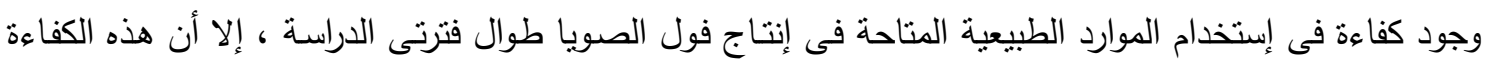
قد زادت خلال الفترة الثانية من الدراسة مما يقلل من الفرصة البديلة لإستخدام تللك الموارد فى إستخدام آخر .

(•) معامل الميزة النسبية الطبيعية فى ظل التظلى عن سياسة التذخل الدكومى:

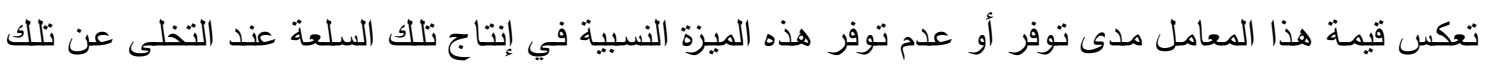

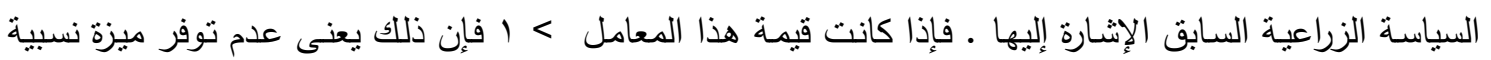
طبيعية للدولة في إنتاج هذه السلعة فى هذه الحالة وهذا يعنى أنه من الأفضل استيراد هذه السلعة بدلا من إنتاجها

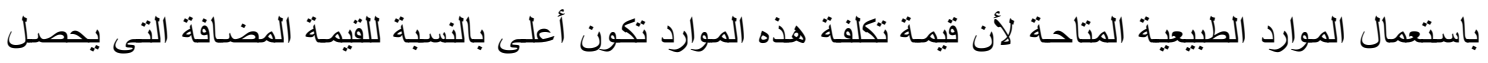

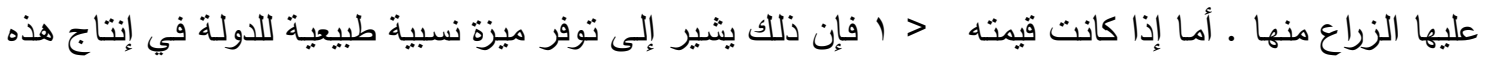

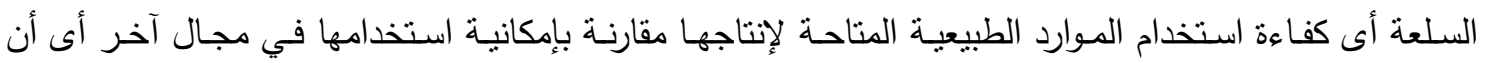

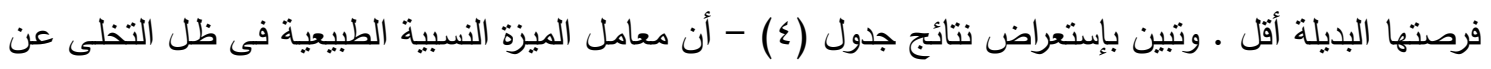

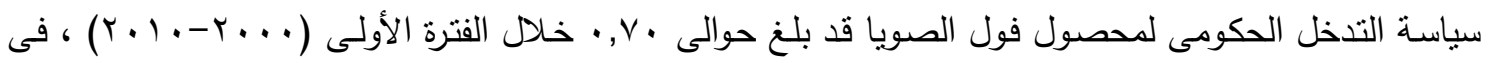

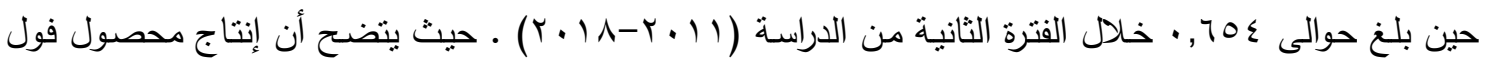
الصويا فى مصر له ميزة نسبية طبيعية طوال فترتى الدراسة ، إلا أن هذه الميزة النسبية الطبيعية قد تزايدت نسبياً

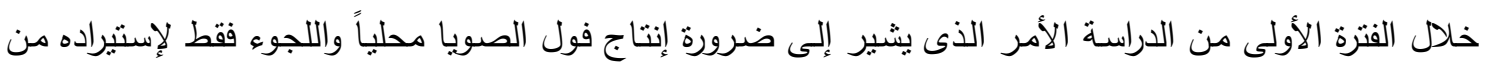

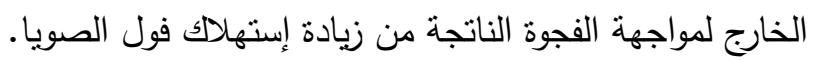


جدول رقم (؛). نتائج مصفوفة تحليل السياسات لقياس أثر السياسات الزراعية على محصول فول الصويا

\begin{tabular}{|c|c|c|}
\hline متوسط الفترة & متوسط الفترة & البيــان \\
\hline $1, \cdots r$ & $\cdot 9 \wedge \mathrm{V}$ & امل الحماية الإسمية للإنتاج \\
\hline$\cdot, 9 \cdot 1$ & $\cdot, 9 \cdot 9$ & عامل الحماية الإسمية لمستلزمات الإنتاج \\
\hline $1, \cdot 11$ & $1, \ldots r$ & 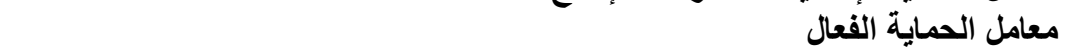 \\
\hline$\cdot, \mathrm{V} \cdot \mathrm{O}$ & $\cdot, \mathrm{vo}$ & عامل الميزة النسبية الطبيعية (تكلفة الموارد المحلية) في ظل سياسة التذخل الحكومى \\
\hline$\therefore$ & $\therefore, \vee \cdots$ & معامل الميزة النسبية الطبيعية في ظل التظلى عن سياسة التلخل ألكومى ع \\
\hline$\cdot, Y K A$ & $\cdot, 100$ & المعدل النسبى للاعم الدكومى للمنتجين ل \\
\hline$\therefore, v .0$ & $\therefore$, vo. & معامل تكلفة سياسة الدعم \\
\hline
\end{tabular}

المصدر : جمعت وحسبت من جدول رقم (1).

\section{(7) المعدل النسبى للاعم الحكومى لمنتجى محصول فول الصويا:}

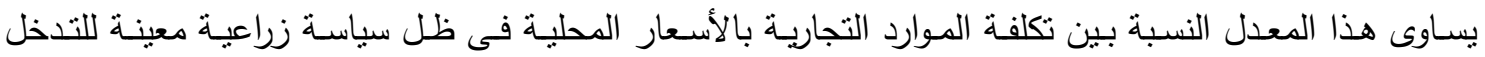
الحكومى لدعم تللك الموارد إلى العوائد المزرعية فى ظل التخلى عن هذه السياسـة ـ وتبين بإستعراض نتائج جدول

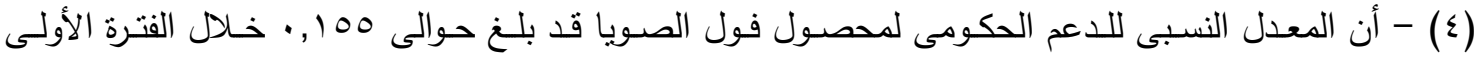

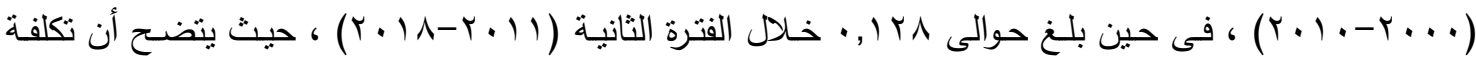

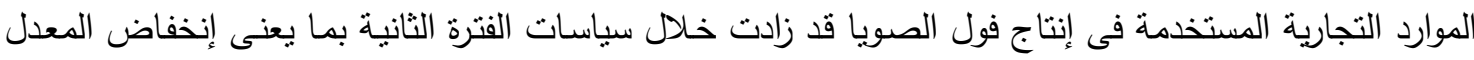
النسبى للاعم الحكومى خلال تلاك الفترة عما كان عليه في الفترة الأولى.

: معامل تكلفة سياسة الاعم (V)

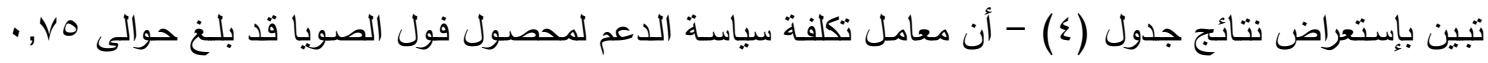

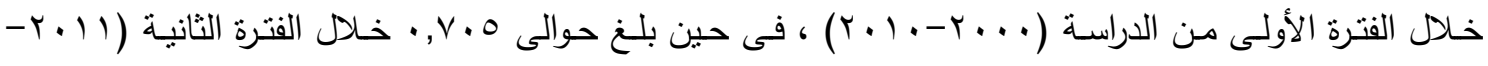

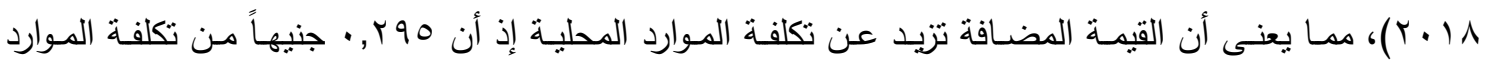

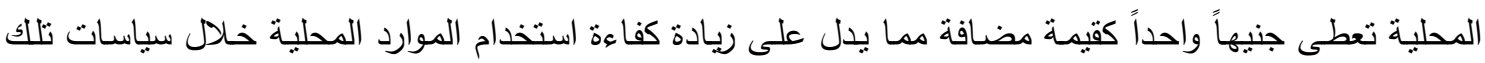
الفترة.

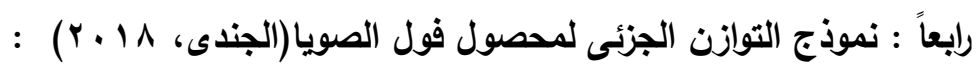
تبين بإستعراض نتائج تحليل وتطبيق نموذج التوازن الجزئى فى قياس أثر السياسات الزراعية المتبعة على محصول

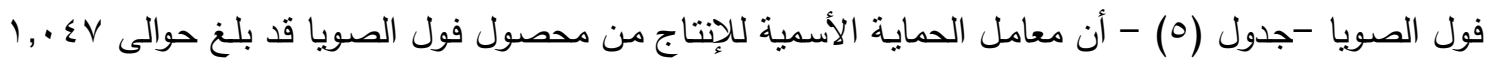

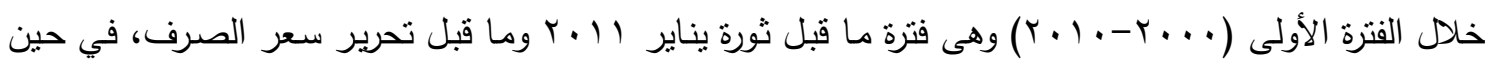

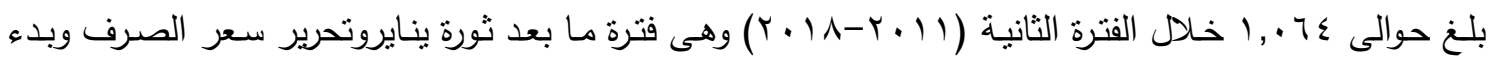

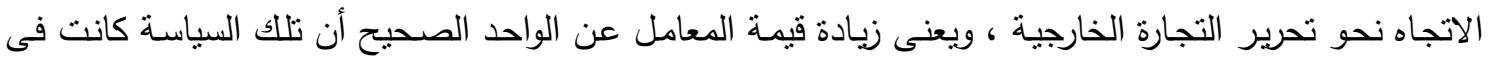
صالح المنتج الإ أنها تميل لمصلحة المنتج أكثر خلال الفترة الثانية عن الفترة الأولى من الدراسة.

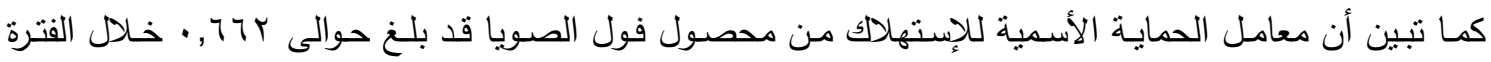

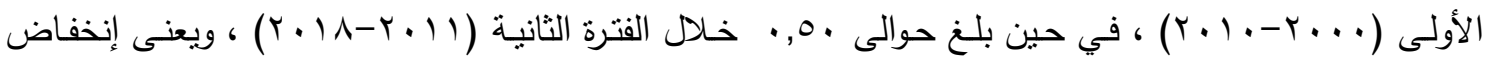

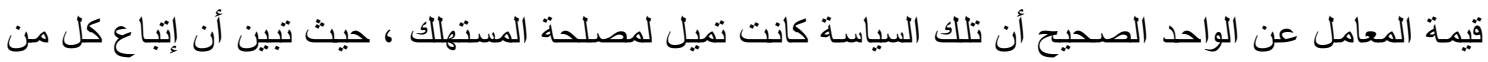
السياستين كانتا فى صالح المستهلك لمحصول فول الصويا خلال فترتى الدراسة- - جدول (0) . 


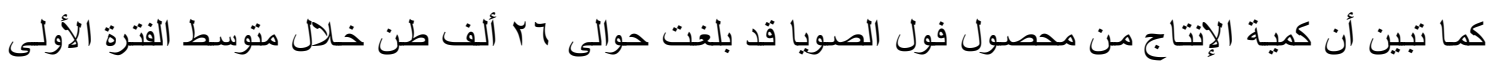

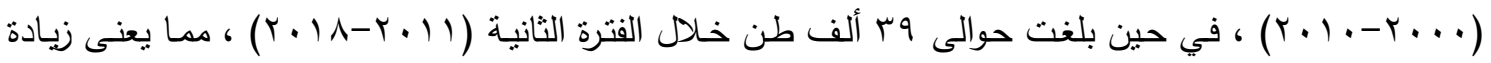

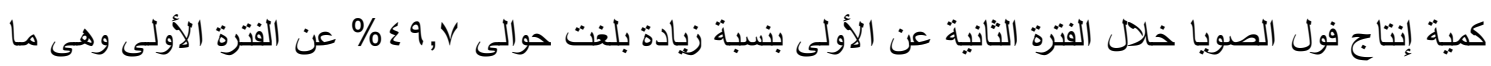

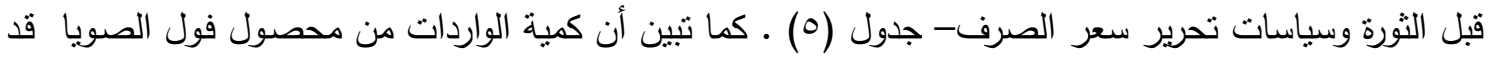

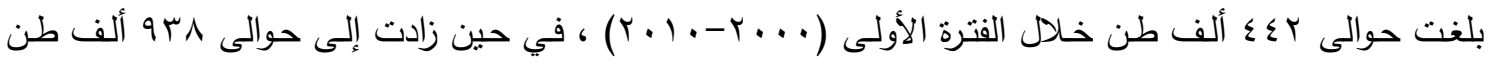

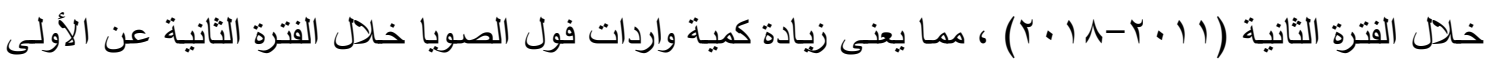

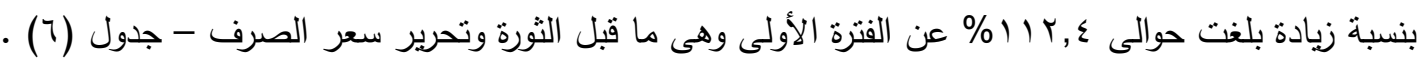

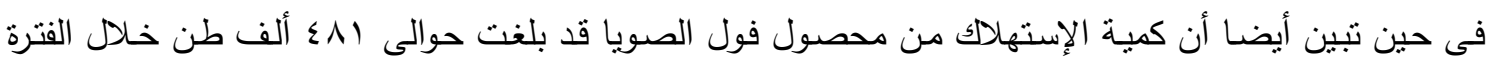

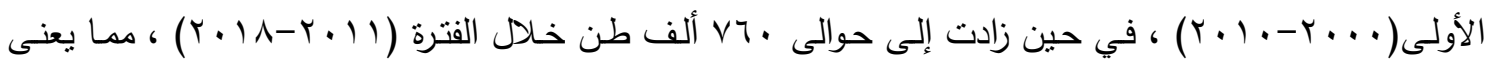

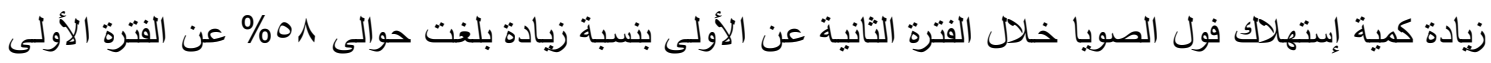
وهى ما قبل الثورة وتحرير سعر الصرف - جدول (0) .

ويتبين مما سبق أثز سياسات الفترة الثانية على زيادة كمية الإنتاج من محصول فول الصويا فى حين تبين زيادة الإستهلاك من محصول فول الصويا مما انعكس على زيادة حجم الواردات من محصول فول الصويا خلال الفترة

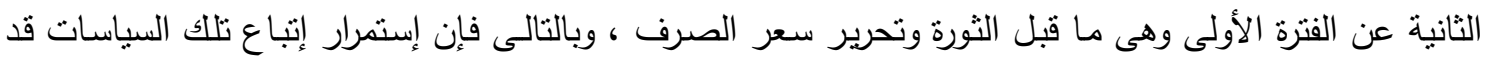

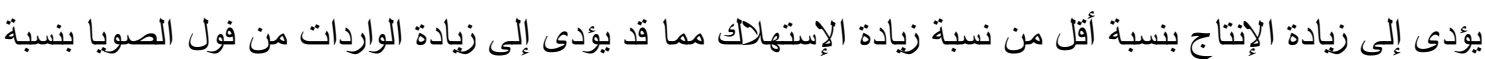
أكبر من نسبة زيادة الإستهلاكك.

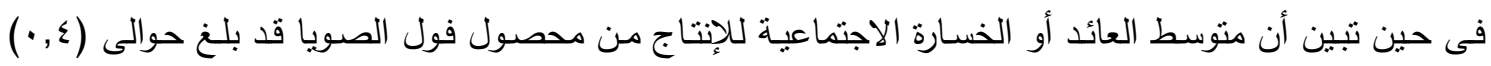

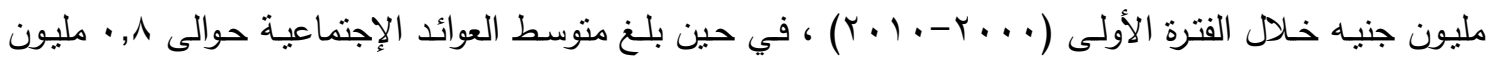

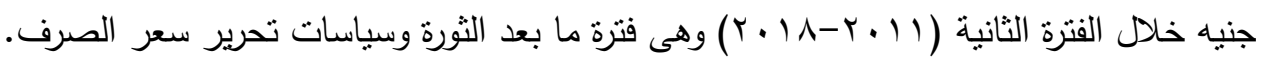

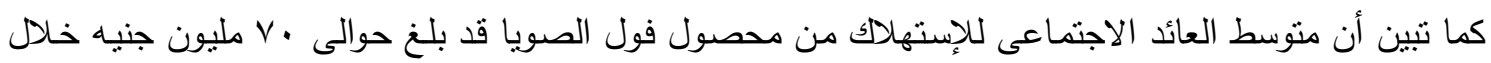

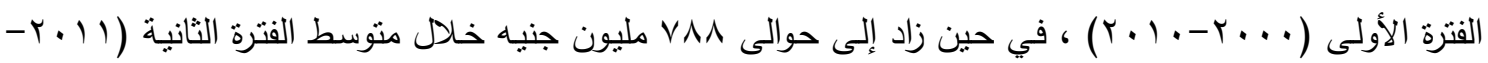

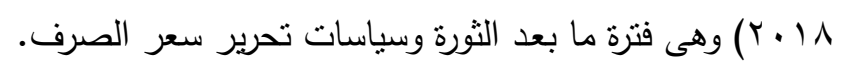

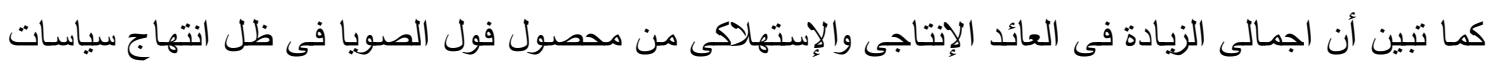

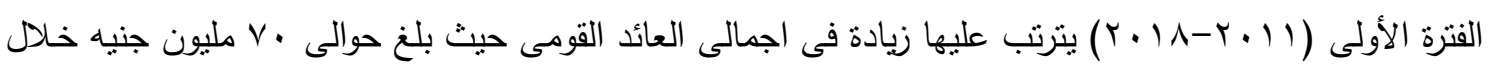

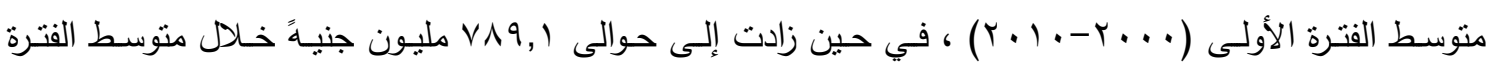

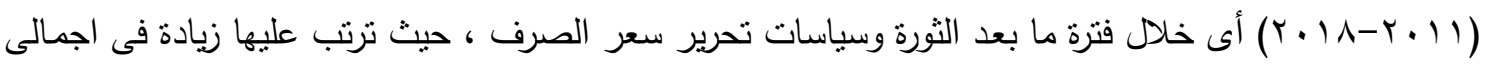

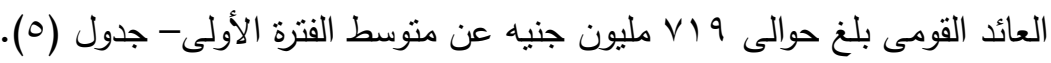

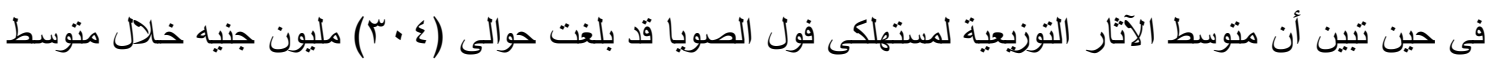

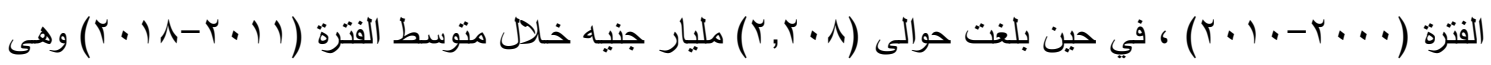
فترة ما بعد الثورة وسياسات تحرير سعر الصرف ـ ويبين هذا المعامل أثز تتفيذ سياسة اقتصادية معينة على مقدار

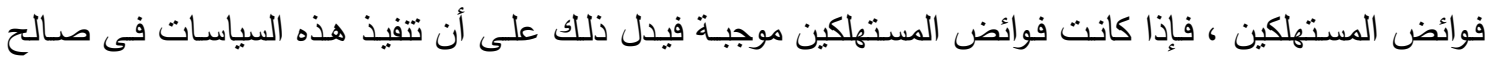

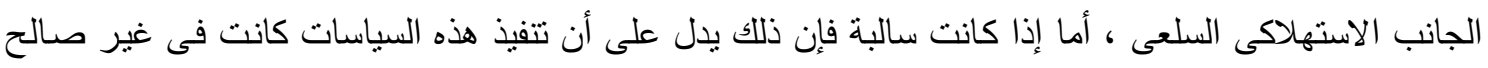

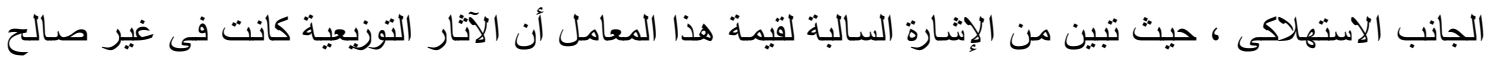


مستهلكى فول الصويا خلال فترتى الدراسة ، الإ أنها كانت تميل فى غير صالح المستهلك أكثر خلال الفترة الثانية

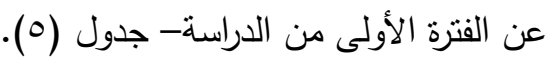

كما تبين أن متوسط الآثار التوزيعية لمنتجى فول الصويا قد بلغت حوالى (9, ( ) مليون جنيه خلال متوسط الفترة

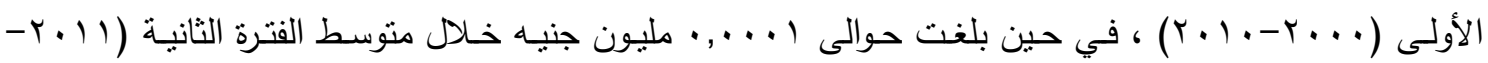

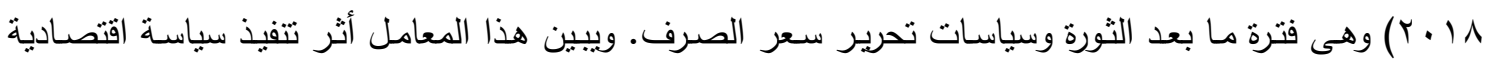

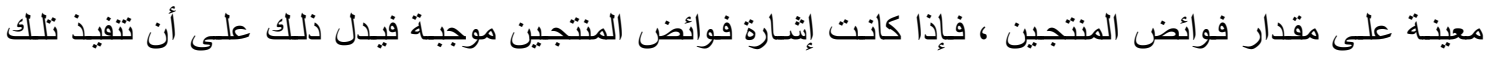

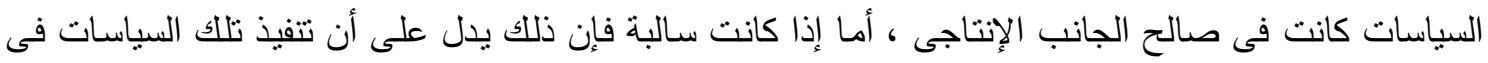

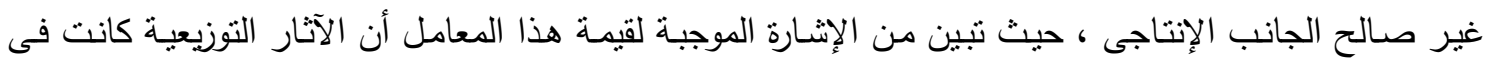

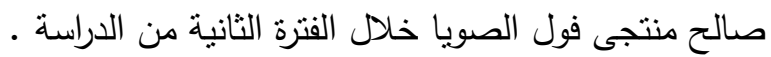

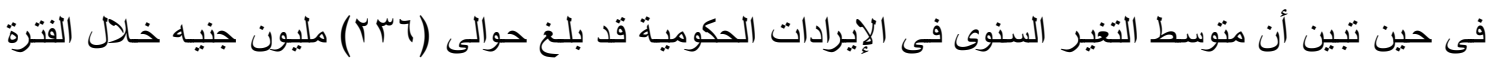

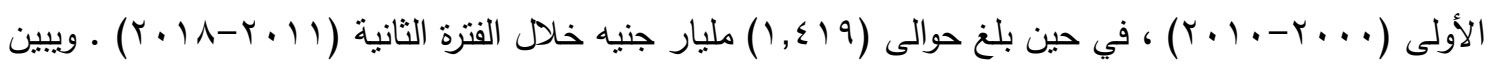

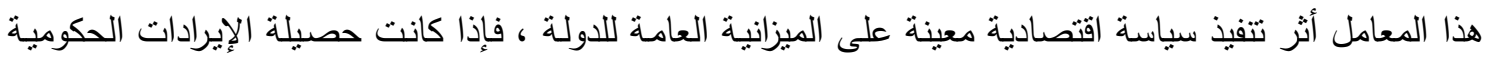

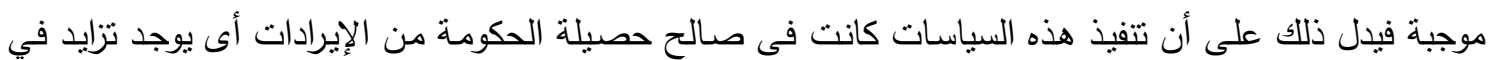

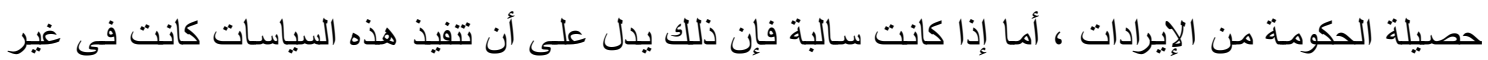

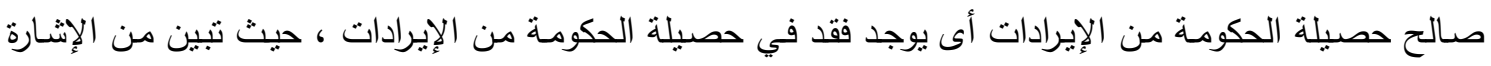

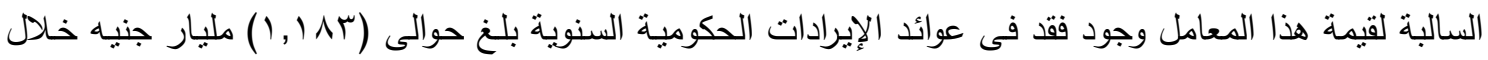

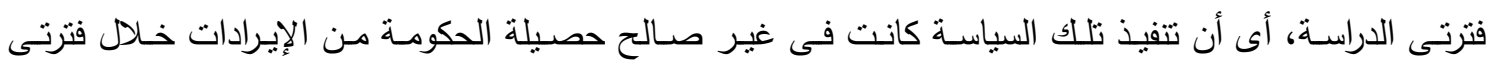

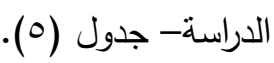

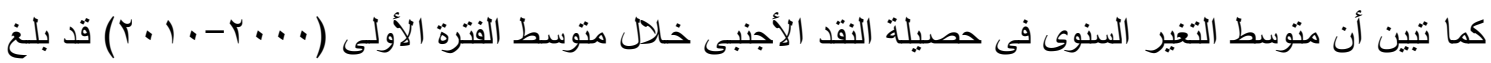

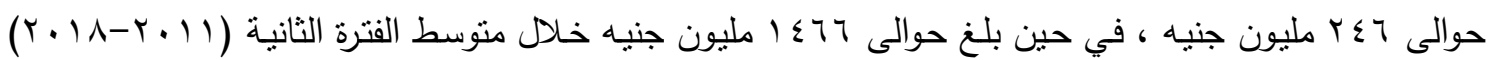
وهى فترة ما بعد الثورة وسياسات تحرير سعر الصرف وبدء الإتجاه نحو تحرير التجارة الخارجية الأمر الذى يعنى هئى زيادة حصيلة النقد الأجنبى بحوالى • ب ا مليون جنيه خلال متوسط تللك الفترة- جدول (0) •

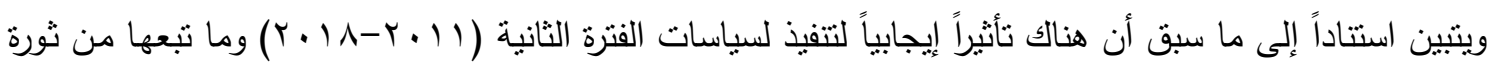
وسياسات تحرير سعر الصرف على محصول فول الصويا خاصـة على الجانب الإنتاجى ،الجانب الإستهلاكى ، إجمالى العوائد الاجتماعية ، الآثار التوزيعية للمنتجين ، وحصيلة النقد الأجنبى لمحصول فول الصويا، فى حين كان لتتفيذ هذه السياسات تأثيراً سلبياً على الآثار التوزيعية لمستهلكى فول التئه الصويا وإيرادات وعوائد الحكومة خلال فترنى الدراسة. 
جدول (0). نتائج التوازن الجزئى لمحصول فول الصويا خلال فترنى الدراسة

\begin{tabular}{|c|c|c|c|}
\hline متوسط الفترة الثاتية & 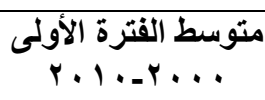 & الفئة & البيــان \\
\hline $1, \cdot 7 \varepsilon$ & $1, \cdot \leq V$ & - & الحماية الاسمية للإنتاج \\
\hline$\cdot, 0 \ldots$ & $\cdot, 774$ & - & الحماية الاسمية للإستهلاك \\
\hline \multicolumn{4}{|r|}{ أَثر السياسات على الأمن الذذائى للفول الصويا : } \\
\hline rq & rq & ألف طن & 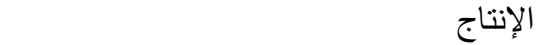 \\
\hline 941 & $\varepsilon \varepsilon r$ & 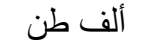 & 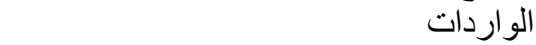 \\
\hline vч. & $\varepsilon \Lambda 1$ & ألف طن & الإستهلاك \\
\hline \multicolumn{4}{|r|}{ الآثًار الاقتصادية الناشئة: } \\
\hline$\cdot, \wedge$ & $-\cdot, \varepsilon$ & مليون جنيه & العائد أو الخسارة الاجتماعية فى الإنتاج \\
\hline$\vee \wedge \Lambda$ & $v \cdot$ & مليون جنيه & العائد أو الخسارة الاجتماعية فى الإستهلاك \\
\hline$\vee \wedge 9,1$ & $\vee \cdot$ & مليون جنيه & اجمالى العائد أو الخسارة الاجتماعية \\
\hline$-r t \cdot \Lambda$ & $-\mu \cdot \varepsilon$ & مليون جنيه & الآثار التوزيعية للمستهلكين \\
\hline$\cdot, \cdots 1$ & $-1,9$ & مليون جنيه & الآثار التوزيعية للمنتجين \\
\hline$-1 \leq 19$ & דוtr & مليون جنيه & التغير فى الإير ادات الحكومية \\
\hline $1 \leq 77$ & $r \leq 7$ & مليون جنبه & التغير فى حصيلة النقد الأجنبى \\
\hline
\end{tabular}

المصدر : جمعت وحسبت من جدول رقم (1).

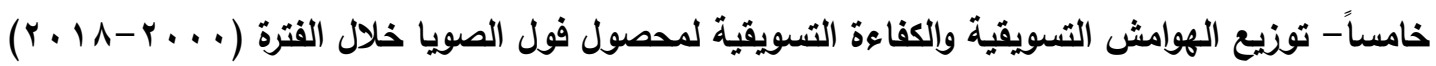

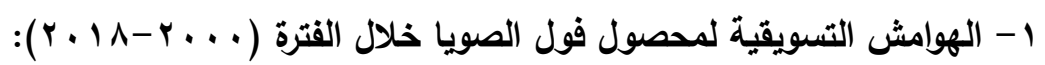

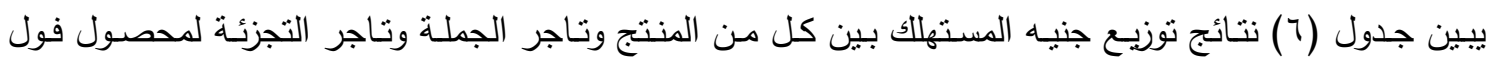

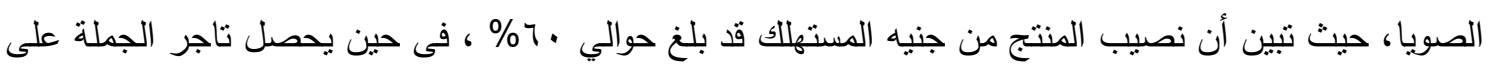

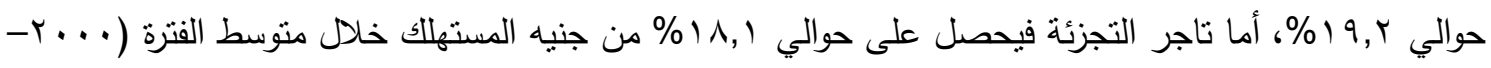

كما تبين أن الهوامش التسويقية المطلقة لمحصول فول الصويا قد تراوحت بين حد أدنى بلغ حوالي 919 جنيه/طن

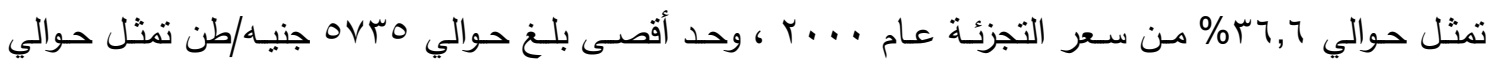

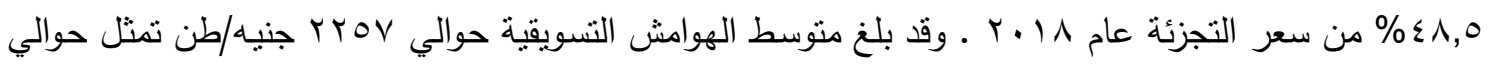

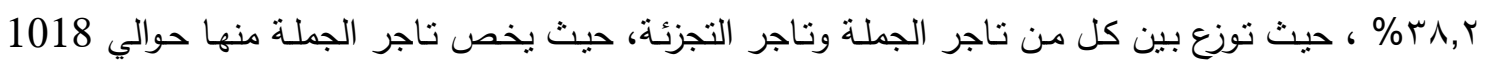

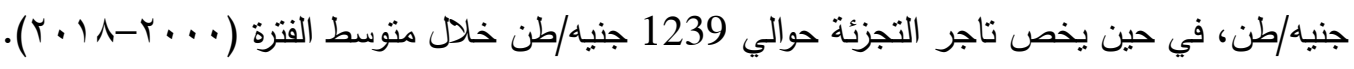

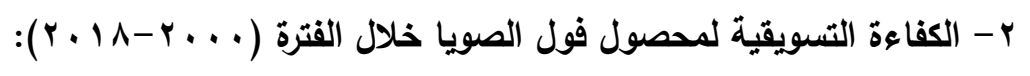

يعتمد حساب التكاليف التسويقية على تكاليف التسويق وتكاليف الإنتاج ، حيث أن تدنية التكاليف التسويقية تؤدى إلى معظمة الكفاءة ، و تحسب الكفاءة التسويقية بخارج قسمة التكاليف التسويقية على (مجموع التكاليف التسويقية

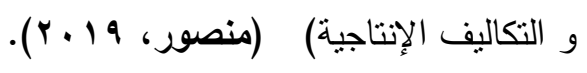

\section{الكفاءة التسويقية = . . 1 - [( التكاليف التسويقية)/(التكاليف التسويقية+التكاليف الإنتاجية)]* . .}

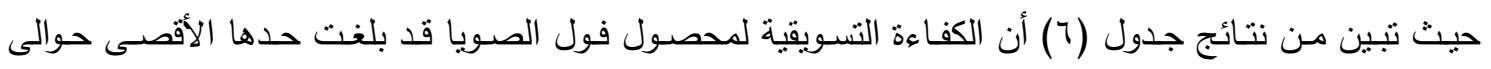

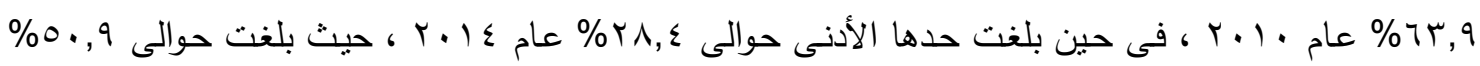




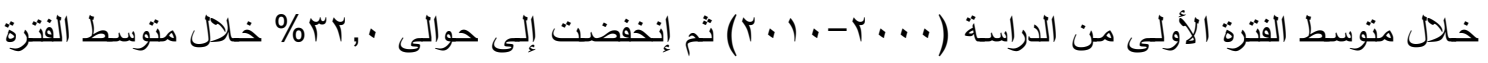

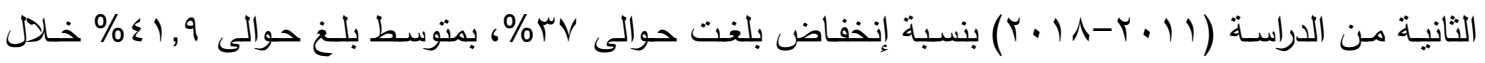

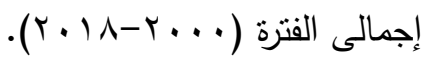

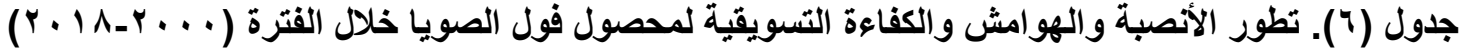

\begin{tabular}{|c|c|c|c|c|c|c|c|c|c|c|c|}
\hline \multirow{3}{*}{$\begin{array}{c}\text { التسويقية } \\
\%\end{array}$} & \multicolumn{6}{|c|}{ الهوامش التسويقية } & \multirow{2}{*}{\multicolumn{4}{|c|}{ توزيع الأنصبة }} & \multirow{3}{*}{ السنة } \\
\hline & \multicolumn{2}{|c|}{ تجزئة - منتج } & \multicolumn{2}{|c|}{ تجزئة - جملة } & \multicolumn{2}{|c|}{ جملة - منتج } & & & & & \\
\hline & $\%$ & مطلق & $\%$ & مطلق & $\%$ & مطلق & الوسطاء & التجزئة & الجملة & المنتج & \\
\hline 07,9 & $r 7,7$ & 019 & $\mathrm{IV}$, & $r \leq 1$ & $T r, T$ & TVA & 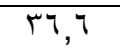 & $I V$, & 19,7 & $7 \leqslant, \varepsilon$ & $r \ldots$ \\
\hline $0 \leqslant, 9$ & $r v, q$ & $0 \leqslant 9$ & 11,7 & rฯq & $r T, V$ & rVq & $r v, q$ & 11,7 & $19, r$ & $T r, 1$ & $r \ldots 1$ \\
\hline$\leq \varepsilon, 1$ & $\varepsilon \cdot, r$ & $\vee \vee \varepsilon$ & 11,1 & $r \leqslant q$ & $r v, \cdot$ & $\leqslant$ Yo & $\varepsilon \cdot, r$ & 11,1 & $r r_{,}$ & $09, \wedge$ & $r \ldots r$ \\
\hline$\varepsilon \cdot, V$ & r & ᄉ० & $1 \cdot, r$ & rov & $r\urcorner, \varepsilon$ & $09 V$ & r & $1 \cdot, r$ & $r r, V$ & 77,1 & $r \ldots r$ \\
\hline$\varepsilon r, T$ & q & 904 & $K_{,} \varepsilon$ & $r \leqslant \wedge$ & $r \leqslant, 0$ & 7.0 & q & $M, \varepsilon$ & $r 1,0$ & 77,1 & $r \ldots \varepsilon$ \\
\hline 01, & $r \wedge, q$ & vov & $1 \cdot, 7$ & YVT & $r \cdot, 0$ & $\varepsilon \wedge$. & $r \wedge, q$ & $1 \cdot, 7$ & $1 \wedge, \varepsilon$ & $v 1,1$ & $r \ldots o$ \\
\hline ov, 7 & rı, & $T V$. & 9,9 & YOS & $1 v, 9$ & $\leqslant 17$ & $r_{7}, \cdot$ & 9,9 & 17,1 & $V \varepsilon, \cdot$ & $r \ldots r$ \\
\hline$\leqslant\rceil, \wedge$ & rT, & 911 & 11,0 & rrv & $r \leqslant, \wedge$ & $7 \leq \varepsilon$ & rT, & 11,0 & $r_{1}, 9$ & 77,7 & $r . . v$ \\
\hline$\leqslant V, 0$ & $r 0,7$ & $119 \leq$ & ${ }^{\prime} r_{,}$ & $\varepsilon \cdot r$ & $r\urcorner, \wedge$ & var & $r 0,7$ & Ir, & $r T, T$ & $7 \leqslant, \varepsilon$ & $r . \Lambda$ \\
\hline ov , $\wedge$ & $r \leq, q$ & $V M$. & $10, \varepsilon$ & sor & $11, r$ & TVV & $r \leqslant, q$ & $10, \varepsilon$ & $9, \varepsilon$ & $v 0,1$ & $r \ldots q$ \\
\hline 74,9 & $r_{0,0}$ & VqT & $M, r$ & $\leqslant$. & $1 \leqslant, r$ & rᄉr & $r_{0,0}$ & $M, r$ & Ir, r & $V \varepsilon, 0$ & $r+1$. \\
\hline$r_{0,1}$ & $\leqslant q, v$ & TATY & ro,. & $1 \leq r A$ & $r, q$ & $1 \leq \cdot 1$ & $\leqslant q, \vee$ & ro,. & $r \leqslant, V$ & $0 ., r$ & $r .11$ \\
\hline$r q, \cdot$ & $\varepsilon \varepsilon, 1$ & rror & $r \varepsilon, \cdot$ & IVIN & $r 7,0$ & $1 \leqslant \wedge \leqslant$ & $\varepsilon \varepsilon, 1$ & $r \leqslant, \cdot$ & $r \cdot, 1$ & 00,9 & $r .1 r$ \\
\hline$r \cdot, 0$ & $\leqslant 0, r$ & $r \leqslant q$. & ro, 1 & 19rr & $r v, \cdot$ & $100 \mathrm{~V}$ & $\leqslant 0, r$ & ro, 1 & $r \cdot, r$ & $0 \leqslant, V$ & $r .1 r$ \\
\hline$r \wedge, \varepsilon$ & $\leqslant q, v$ & $\leqslant Y 10$ & $r \cdot, \wedge$ & $r 7.1$ & $r V, \varepsilon$ & 17.8 & $\varepsilon q, V$ & $r \cdot, \wedge$ & 19, & $0 ., r$ & $r .1 \leq$ \\
\hline$r \wedge, 0$ & $01,\{$ & $\leqslant 0 \wedge 1$ & $r, r$ & TVAI & $r q, r$ & 1899 & $01, \varepsilon$ & $r, r$ & $r \cdot, r$ & $\{\Lambda, 7$ & $r .10$ \\
\hline$r \cdot, 7$ & $01, \mathrm{~V}$ & $\leqslant 7 \wedge 9$ & $r, r$ & rqY. & $r \wedge, \vee$ & $1 \vee 71$ & $01, \mathrm{~V}$ & $r, r$ & 19,0 & $\varepsilon \wedge, r$ & $r .17$ \\
\hline ro,v & $\leqslant 9, \wedge$ & or. A & $r \cdot, \cdot$ & T197 & $r \wedge, r$ & rוT & $\leq 9, \wedge$ & $r \cdot, \cdot$ & 19,1 & $0 \cdot, r$ & $r .1 \mathrm{r}$ \\
\hline$\varepsilon \cdot, 0$ & $\sum \Lambda, 0$ & OVTo & rA, & عاسM & $r \wedge, \varepsilon$ & $r \leq Y 1$ & $\sum \wedge, 0$ & rA, & $r \cdot, 0$ & 01,0 & $r \cdot 1 \Lambda$ \\
\hline$\& 1,9$ & $r \wedge, r$ & YYOV & 11,1 & Irrq & $r \leqslant, \cdot$ & 1.11 & $r \wedge, r$ & 11,1 & $19, r$ & $7 \cdot, \cdot$ & المتوسط \\
\hline $0 \cdot, 9$ & $r r_{,} \cdot$ & 091 & $1 T, r$ & TrV & $r 1, r$ & $\leqslant V I$ & $r r_{,}$ & $1 T, r$ & $1 \wedge, r$ & $7 V, \varepsilon$ & 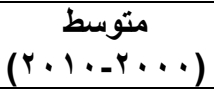 \\
\hline$r r_{,}$ & $\varepsilon \wedge, \vee$ & $\varepsilon r q r$ & $r \wedge, 1$ & $r \leq q \leq$ & $r \wedge, 0$ & $1 V \nabla$. & $\varepsilon \Lambda, \nu$ & $r \wedge, 1$ & $r \cdot, \varepsilon$ & $01, r$ & 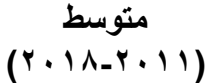 \\
\hline $1 \wedge, \Lambda_{-}$ & 17,1 & $r \leq 77$ & $1 \leqslant, 9$ & FIIV & $v, \varepsilon$ & 1599 & 17,8 & $1 \leqslant, 9$ & $r, r$ & $17, Y=$ & أثز التغير بين \\
\hline$r v, \cdot-$ & or, 1 & $\varepsilon r \leqslant, 0$ & $11 r, r$ & 974,1 & $r \varepsilon, \wedge$ & YVY, & $0 r, 1$ & $11 \%, r$ & 11,1 & $r \varepsilon, 1-$ & نسبة الأثر \\
\hline
\end{tabular}

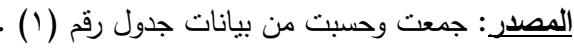

سادساً : التقدير القياسى لدوال الطلب الإستهلاكى والواردات من فول الصويا:

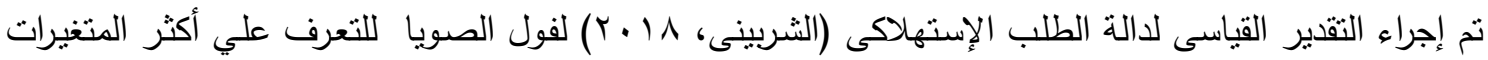
تأثنراً فى إجمالى الطلب الإستهلاكى من فول الصويا بالألف طن (Y) ، وعدة متغيرات تفسيرية متمنلة فى :

$$
\begin{aligned}
& \text { = (X1) }
\end{aligned}
$$

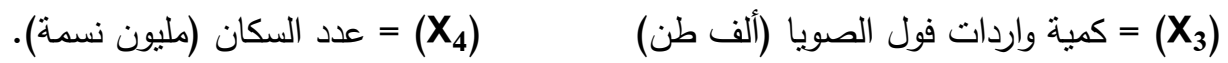

$$
\begin{aligned}
& \text { ( الدخل الفردى النقدى (X) }
\end{aligned}
$$


كما تم إجراء التقدير القياسى لدالة واردات فول الصويا للتعرف علي أكثر المتغيرات تأثيراً فى إجمالى الواردات من فول الصويا بالألف طن (Y) ، وعدة متغيرات تفسيرية متمثلة فى :

(إجمالى ( متوسط نصيب الفرد من فول الصويا (كجم/فرد) ( سعر إستيراد فول الصويا (دولار /طن) ( الدخل الفردى النقدى (جنيه). .

وذللك بعد استخدام الصور الرياضية المختلفة للاوال وهى الخطية والنصف لوغاريتمية واللوغاريتمية المزدوجة، حيث

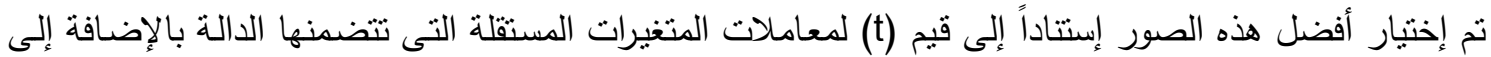
إختبارى F و R م و مد تبين أفضلية النموذج اللوغاريتمى المزدوج فى دالنى الإستهلاك والواردات من محصول فول الصويا.

\section{1 - دالة إجمالى الطلب الإستهلاكى لفول الصويا :}

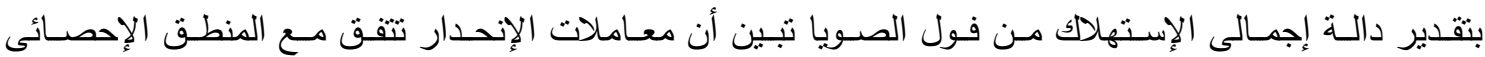

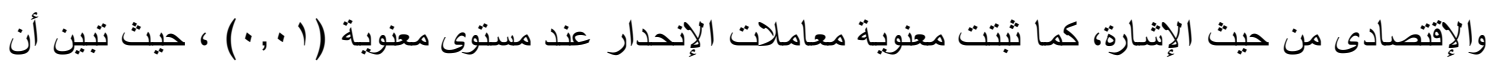

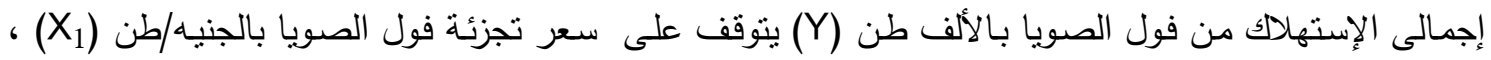

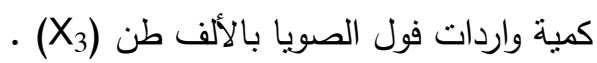
تبين من النموذج اللوغاريتمى المزدوج- جدول (V) وجود علاقة عكسية بين سعر تجزئة فول الصويا (X)

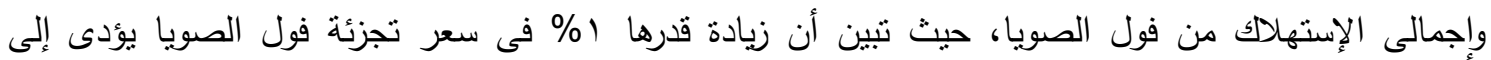
إنخفاض إجمالى إستهلاك فول الصويا بحوالى هץ, • \% .فى حين تبين وجود علاقة طردية بين إجمالى إستهلاك فول الصويا وكمية واردات فول الصويا (XX3) حيث تنين أن زيادة قدرها ا \% فى كمية واردات فول الصويا يؤدى

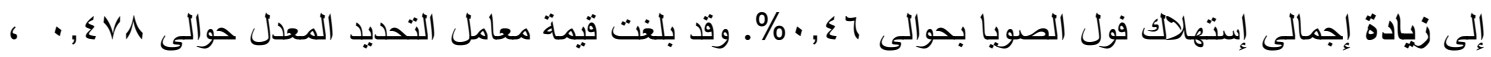

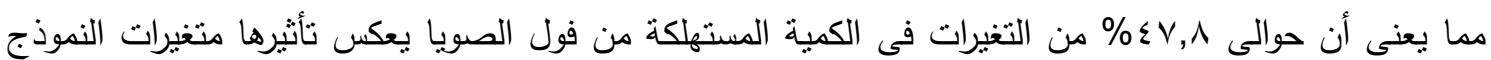
سالفة الذكر.

\section{r - دالة إجمالى الواردات من فول الصويا:}

بتقدير دالة إجمالى الواردات من فول الصويا تبين أن معاملات الإنحدار تتفق مع المنطق الإحصائى والإقتصادى

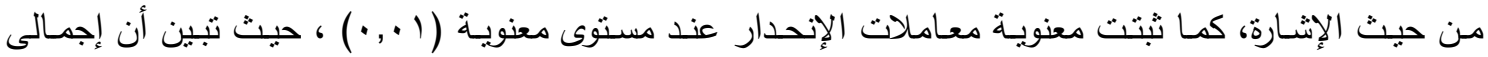

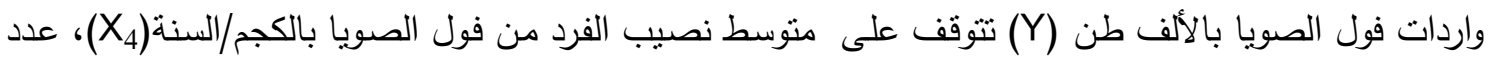

السكان بالمليون نسمة (X)

حيث تبين من النموذج اللوغاريتمى المزدوج- جدول (V) وجود علاقة طردية بين كل من منوسط نصيب الفرد من

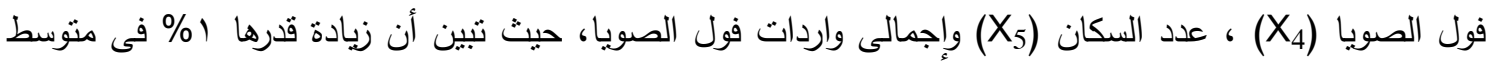

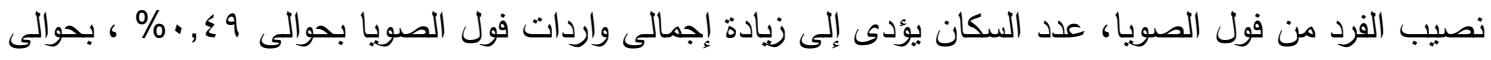

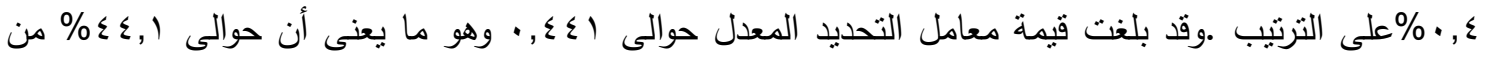

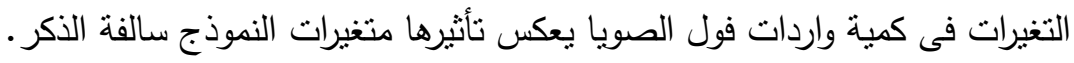


جدول (V). نتائج التقدير القياسى لدالتى إجمالى الطلب الإستهلاكى ودالة إجمالى الواردات الخارجية من

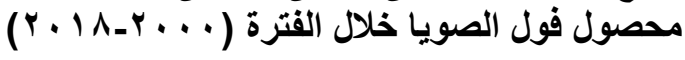

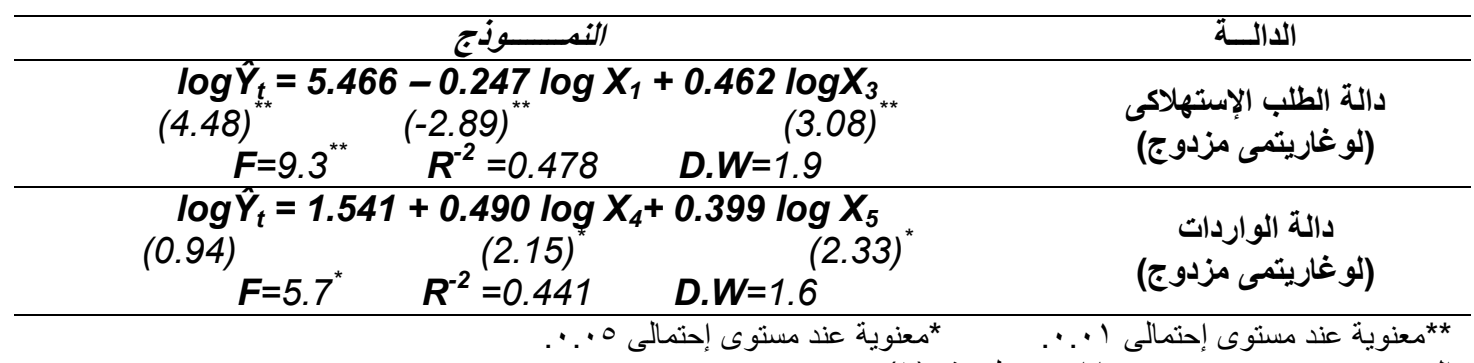

المصدر : جمعت وحسبت من بيانات جدول رقم ( (1).

سابعاً : التبؤ بحجم القجوة من محصول فول الصويا حتى عام هץ • ب : حيث تم الإعتماد فى تقدير التتبؤ على أربعة نماذج قياسية للتقديرات المستقبلية بحجم الفجوة من محصول هول فول فول الصويا وهى : (1)

( ) التقديرات المتوقعة بإستخدام نموذج معدل إزدياد الطلب(كلية الزراعة، . . . . م) على محصول فول الصويا :

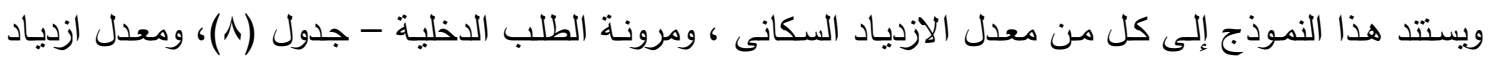
الدخل الفردى الحقيقى ، ويأخذ الصورة الرياضية : (E) (E

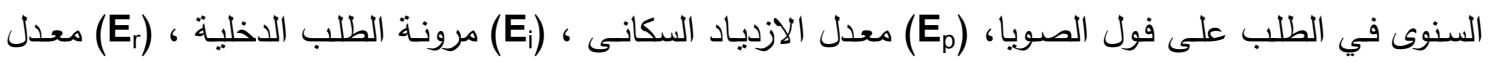

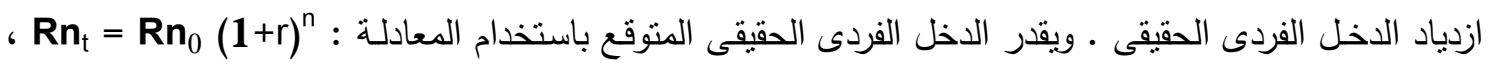

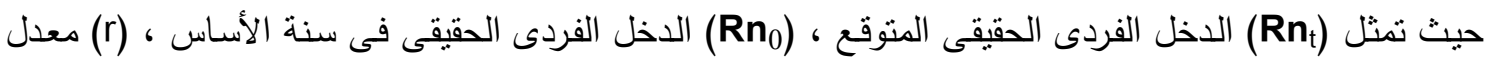

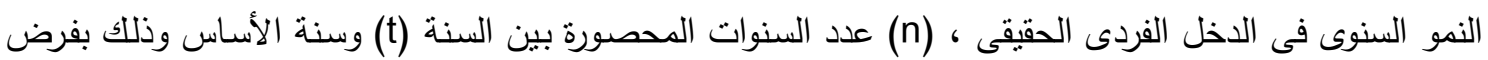
ثبات كل من الأسعار النسبية والمرونات السعرية للفترة المستقلية لصعوبة التتبؤ الدقيق بها. وقد تبين من خلال

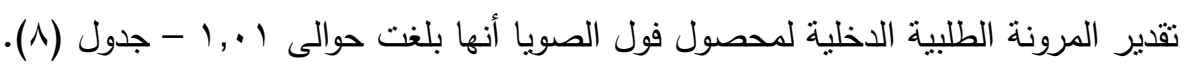
فى حين تبين إستتاداً إلى نموذج معدل إزدياد الطلب على محصول فول الصويا أن متوسط الدخل الفردى الحقيقى

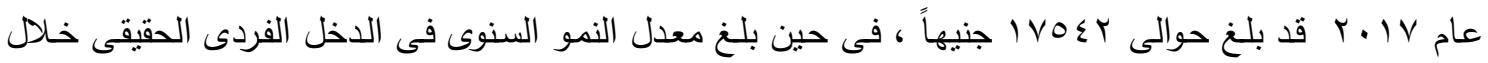

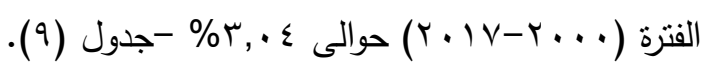

جدول (^) ـ مرونـة الإففاق الكلى للاخل والمرونـة الطلبيـة الإنفاقيـة والمرونـة الطلبيـة الاخليـة لمحصول فول

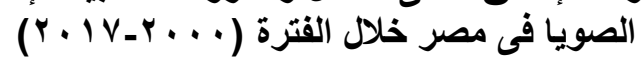

\begin{tabular}{|c|c|c|}
\hline مرونة الإنفاق الكلى للاخل & المرونة الطلبية الدخلية** & المرونة الطلبية الإنفاقية" \\
\hline$\cdot, \vee \wedge \wedge$ & $1, \cdot 1$ & $1, r \vee V$ \\
\hline
\end{tabular}

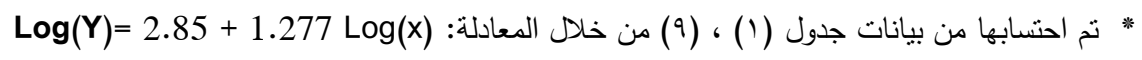

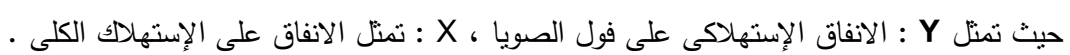

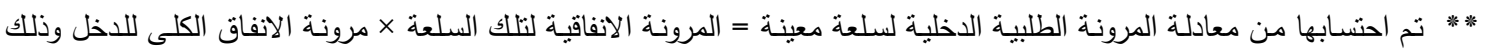

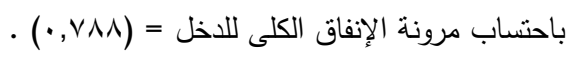

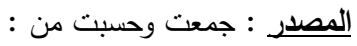

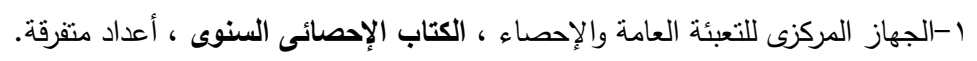

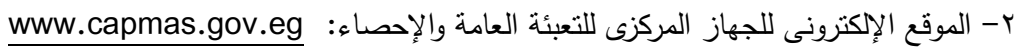

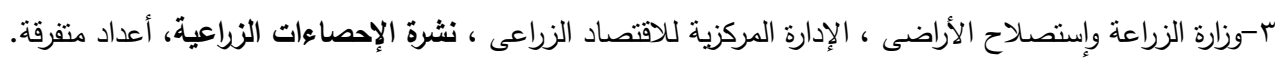




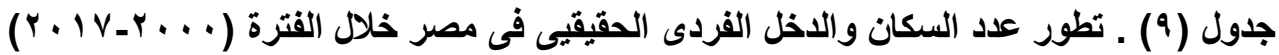

\begin{tabular}{|c|c|c|}
\hline الاخل الفردى الحقيقى & (مليون نسمة) & السنة \\
\hline $11 \wedge \Sigma 7$ & $7 r, r$ & r... \\
\hline MTKY & $T \leqslant, Y$ & r... \\
\hline MIKT & 77, & $r \ldots r$ \\
\hline 11778 & $T V, r$ & $r \ldots r$ \\
\hline $11 \leqslant 14$ & $7 \wedge, 7$ & Y... \\
\hline 1194. & $v \cdot, \cdot$ & r... \\
\hline $\mid r \leq 7$. & $v 1, r$ & Y.. T \\
\hline$M \cdot \sum r$ & $V r, q$ & $r \ldots v$ \\
\hline $1.94 \varepsilon$ & $V \varepsilon, \varepsilon$ & $r \ldots \wedge$ \\
\hline 1.779 & Vฯ, 1 & r..qq \\
\hline $1 \cdot \varepsilon 1$. & $V \vee, \Lambda$ & $r+1$. \\
\hline lOKKA & $\vee 9,7$ & $r+11$ \\
\hline $1 \wedge 9 \vee \varepsilon$ & 11,7 & $r+1 r$ \\
\hline$r \cdot r 10$ & $\wedge r, \mathrm{~V}$ & $r+1 T$ \\
\hline 119900 & 10,1 & $r+1 \varepsilon$ \\
\hline $1 N \mid Y A$ & $\wedge \Lambda, \cdot$ & $r+10$ \\
\hline $11.0 \leqslant$ & $9 \cdot, 1$ & $r .17$ \\
\hline $1 V 0 \leqslant Y$ & $97, r$ & $r . I V$ \\
\hline $1 \leqslant 107$ & $V 7,0$ & المتوسط \\
\hline$\% r, \cdot \varepsilon$ & $\% r, \xi$ & معدل النمو \\
\hline
\end{tabular}

* تم حساب الرقم الحققى بإستخدام الرقم القياسى لأسعار المستهلك لسنة أساس 100=2010 :

المصدر : جمعت وحسبت من : المست

ا-الجهاز المركزى للتعبئة العامة والإحصاء ، الكتاب الإحصائى السنوى ، أعداد متفرقة. r- الموقع الإلكترونى للجهاز المركزى للتعبئة العامة والإحصاء:

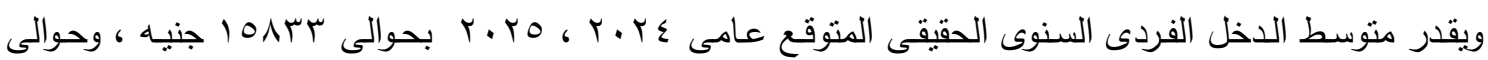

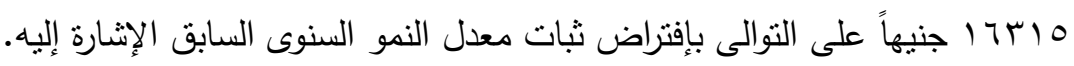

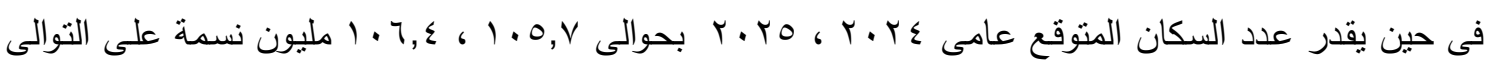

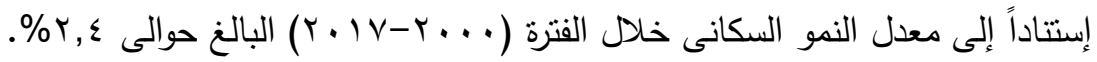

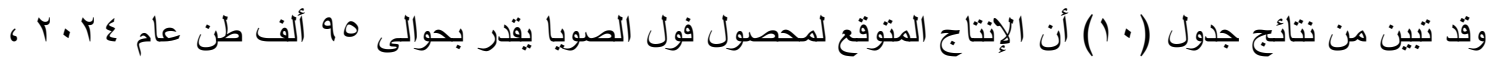

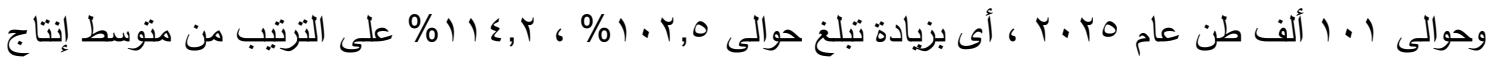

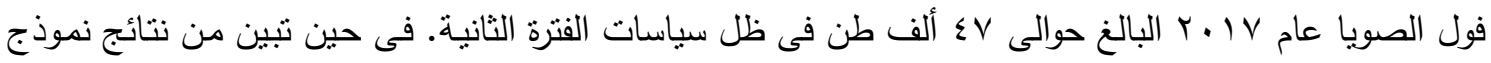

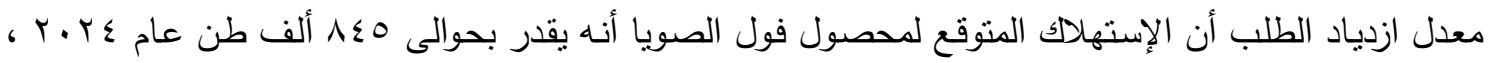

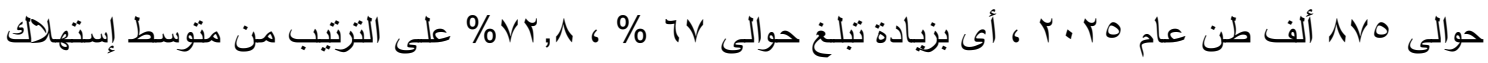

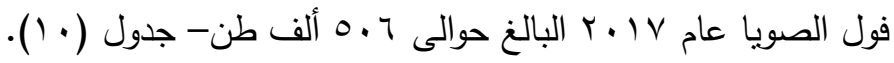

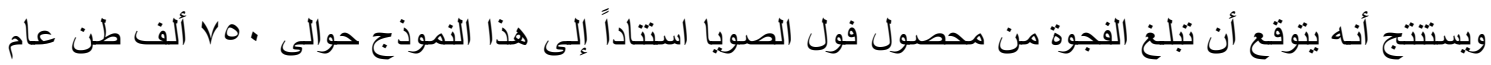

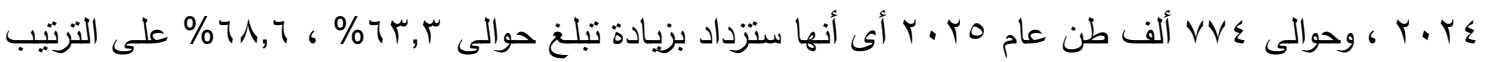

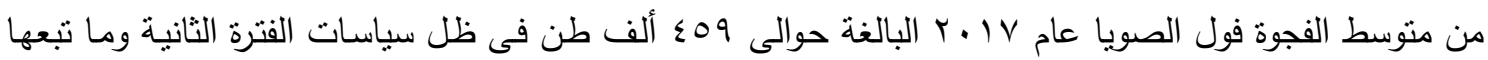
من سياسات تحرر سعر الصرف- جدول (· (1) •

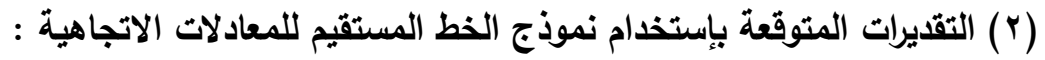




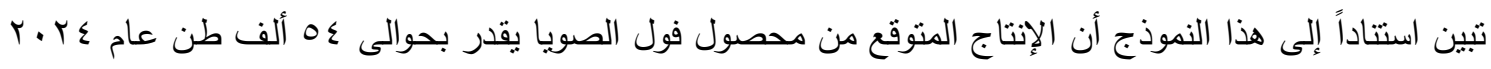

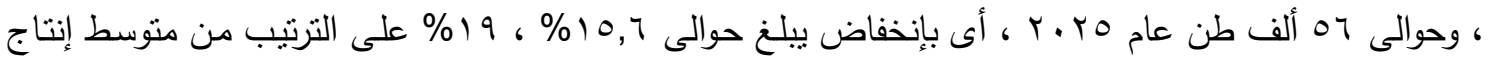

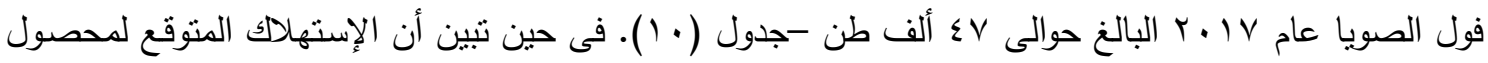

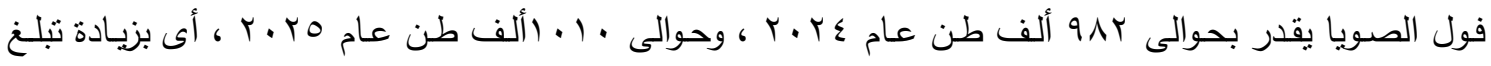

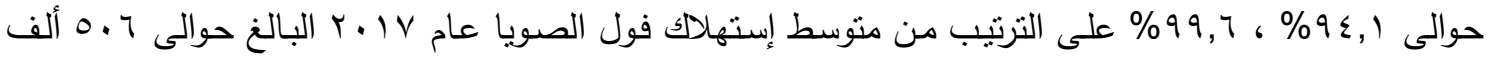

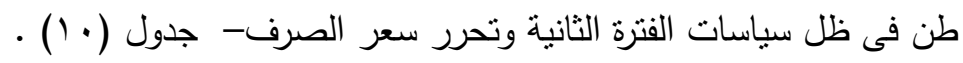

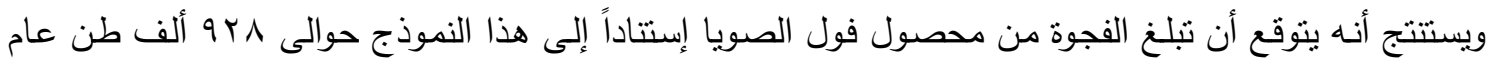

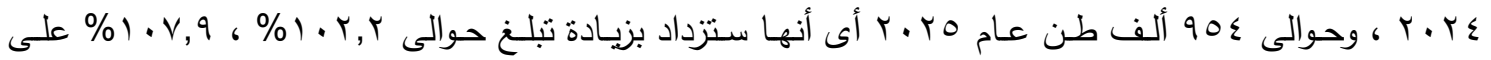

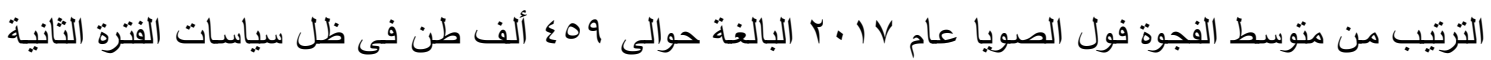

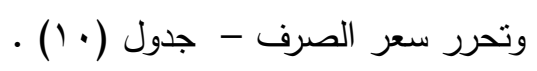

(r) التقديرات المتوقعة بإستخدام نموذج براون ذات المعلم الواحد للتنعيم الأسى المزودج ( منصور، 19 ـ ب ) :

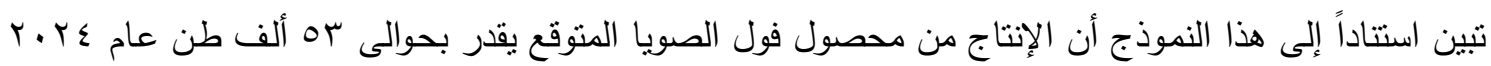

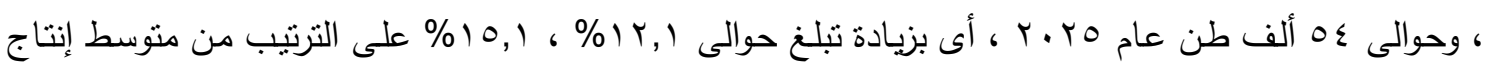

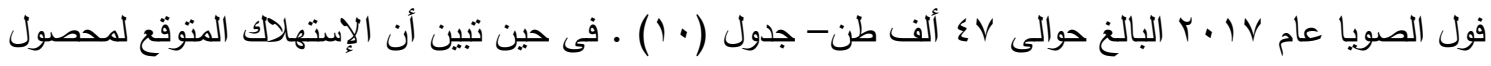

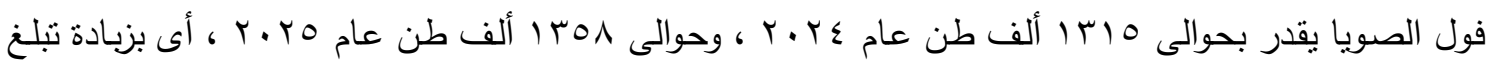

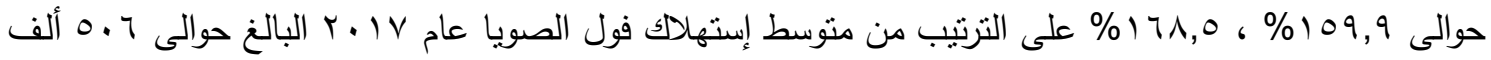

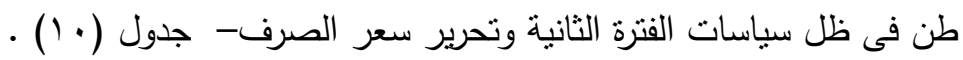

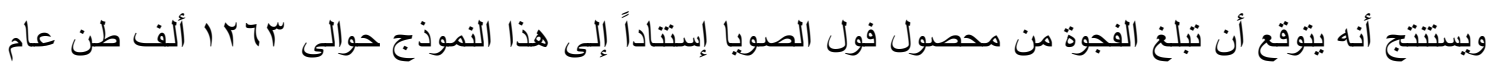

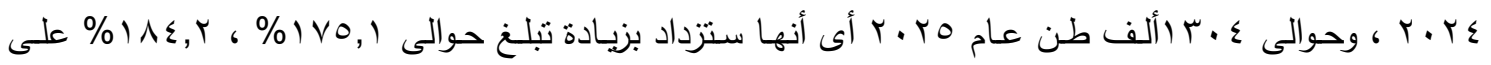

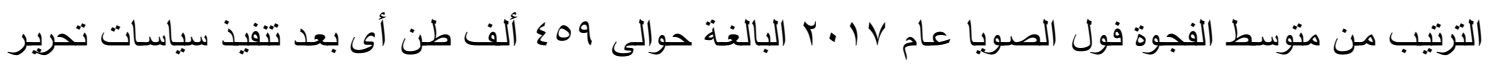

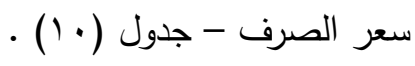

( ) التقديرات المتوقعة بإستخدام نموذج هولت ذات المعلمين للتنعيم الأسى المزودج ( منصور، 19 ـ ب ) )

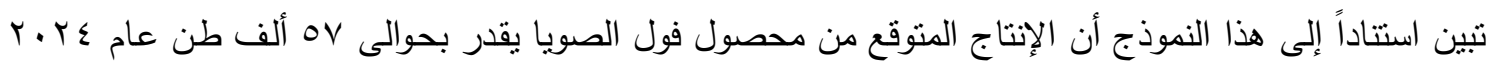

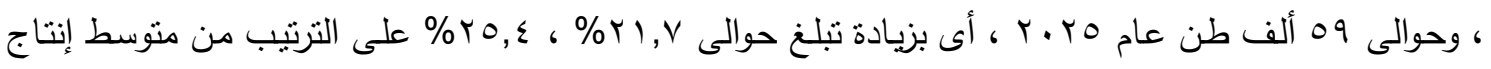

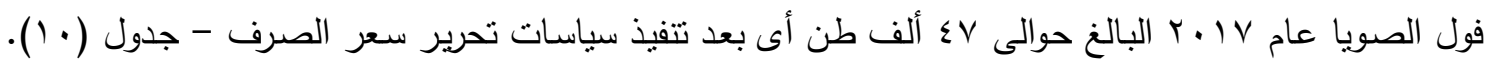

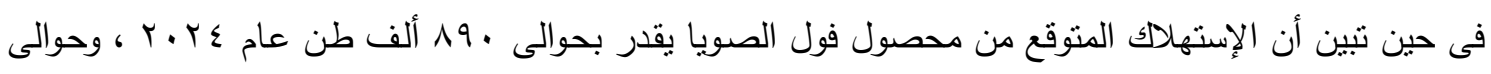

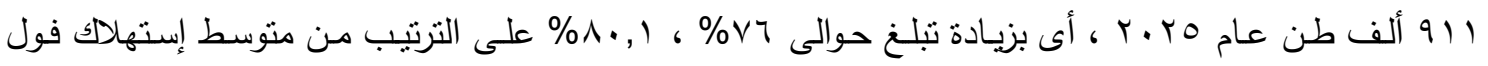

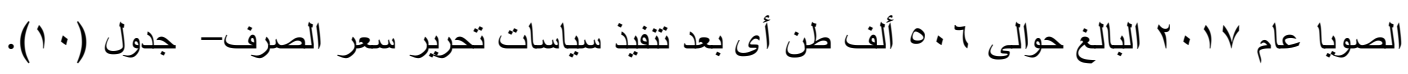

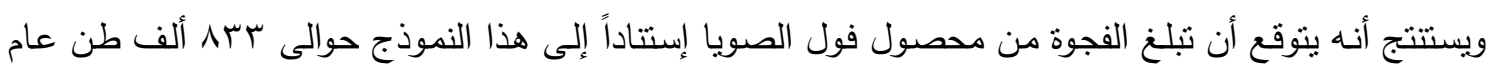

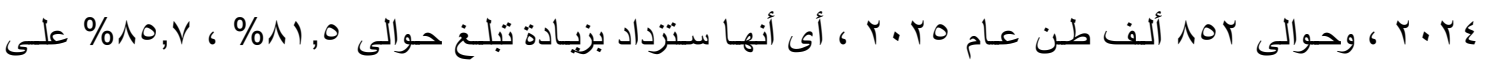

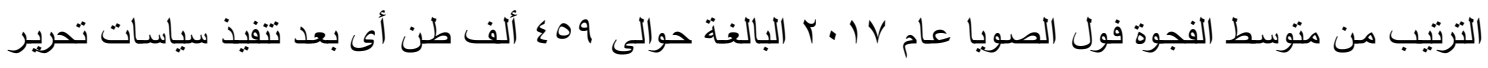

$$
\text { سعر الصرف - جدول (·) (1). }
$$


ويستتتج من نتائج التقديرات التى تم التوصل إليها من مختلف النماذج الإقتصادية القياسية السابقة أن الحد الأدنى

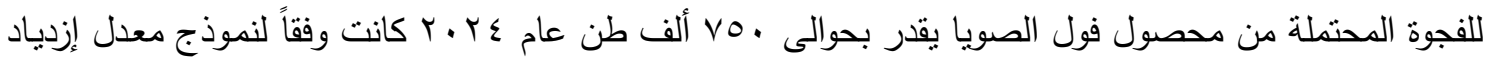

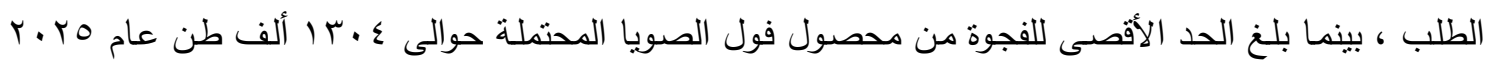
وفقاً لنموذج براون ذات المعلم الواحد للتنعيم الأسى المزدوج.

جدول (· (). أثر السياسـات الراهـة على التقديرات المتوقعة لنمـاذج التنبؤ بإنتاج وإستهلاك وحجم الفجوة

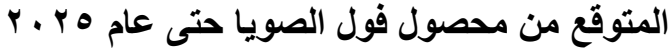

\begin{tabular}{|c|c|c|c|}
\hline ألجوة المتوقعة & الإستُهلاك المتوقع (ألف & الإنتاج طن المتوقع & النموذج \\
\hline & & & نموذج إزدياد الطلب \\
\hline TAY & $V \pi Y^{* *}$ & A. ${ }^{*}$ & $r \cdot T_{1}$ \\
\hline$v \cdot \varepsilon$ & $\vee \wedge q^{\star *}$ & $10^{*}$ & r. ru \\
\hline VYT & $117^{* *}$ & $9 .{ }^{*}$ & $r \cdot r r$ \\
\hline vo. & $\Lambda \leq 0^{* *}$ & $90^{*}$ & $r \cdot r \leqslant$ \\
\hline \multirow[t]{2}{*}{$V \vee \varepsilon$} & $\Lambda \mathrm{VO}^{* *}$ & $1.1^{*}$ & r. ro \\
\hline & & & نموذج المعادلات الإتجاهية \\
\hline 10. & 199 & 0. & $r \cdot r l$ \\
\hline$\Lambda \vee T$ & $94 \mathrm{~V}$ & 01 & r. r r \\
\hline$q . r$ & 900 & or & $r \cdot r r$ \\
\hline $94 \wedge$ & qAr & $0 \leqslant$ & $r \cdot r \leqslant$ \\
\hline \multirow[t]{2}{*}{$90 \leqslant$} & 1.1. & 07 & r. ro \\
\hline & & & نموذج براون ذات المعلم الواحد للتنعيم الأسى المزدوج \\
\hline $11 \mathrm{TV}$ & 1114 & $\sum \Lambda$ & $r \cdot r 1$ \\
\hline 1189 & Irrq & o. & r. rr \\
\hline ITrI & ITVT & 01 & $r \cdot r \mu$ \\
\hline אוTו & 1510 & or & $Y \cdot Y \leqslant$ \\
\hline \multirow[t]{2}{*}{$1 \pi \cdot \varepsilon$} & 1501 & $0 \leqslant$ & r. YO \\
\hline & & & نموذج هولت ذات المعلمين للتنعيم الأسى المزدوج \\
\hline VVT & AYA & Or & $r \cdot r l$ \\
\hline 190 & $\Lambda \leqslant 9$ & $0 \leqslant$ & $r \cdot r r$ \\
\hline$\Lambda 1 \varepsilon$ & 179 & 07 & $r \cdot r r$ \\
\hline שTא & 19. & or & $r \cdot r \varepsilon$ \\
\hline 10r & 911 & 09 & $r \cdot r_{0}$ \\
\hline
\end{tabular}

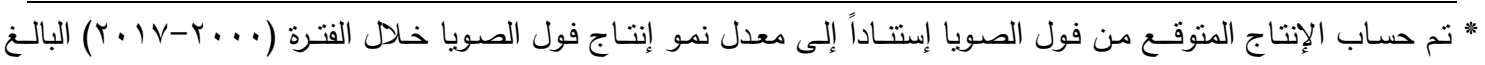

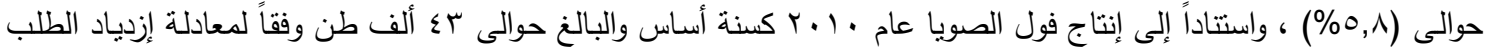

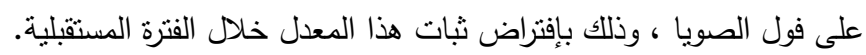

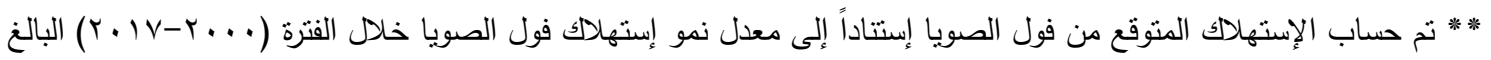

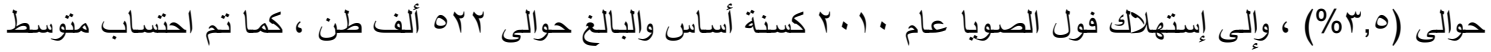

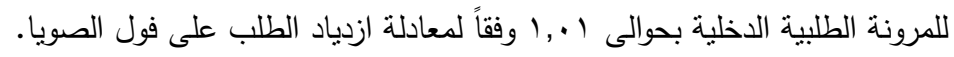

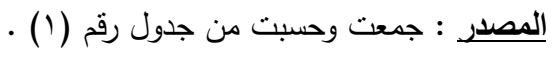


الجندى، هيدى على حسن(1 ( • ب). دراسة إقتصادية لأثر السياسة الزراعية علي محصول الذرة الثامية في

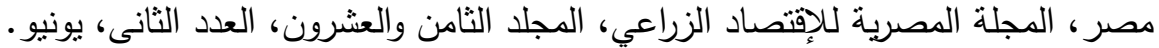
الجهاز المركزي للتعبئة العامة والإحصاء- نشرة إحصاءات التجارة الخاءة الخارجية، أعداد مختلفة.

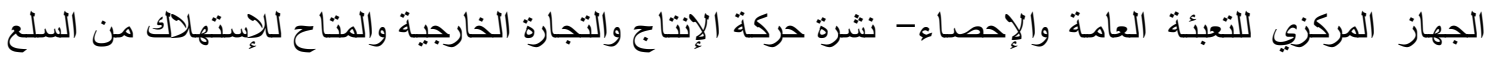
الزراعية ، أعداد مختلفة. الرسول، أحمد أبو اليزيد ، جابر أحمد بسيونى (1991). بعض الجوانب الاقتصادية لمحصول فول الصويا فى (لئ

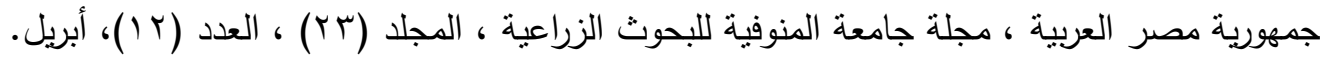

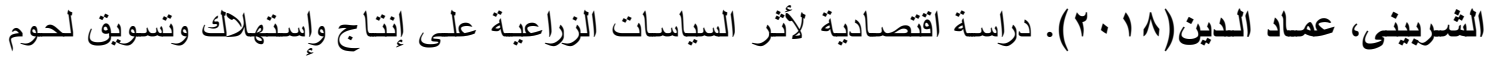

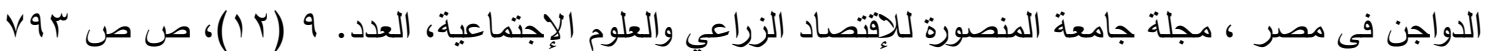

www.capmas.gov.eg الموقع الإكترونى للجهاز المركزى للتعبئة العامة والآحصاء

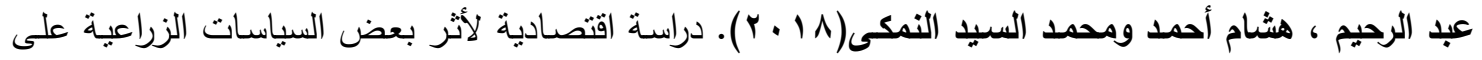

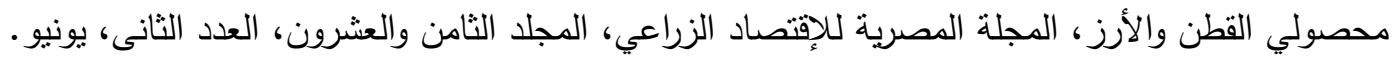

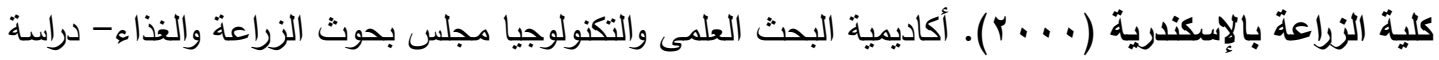

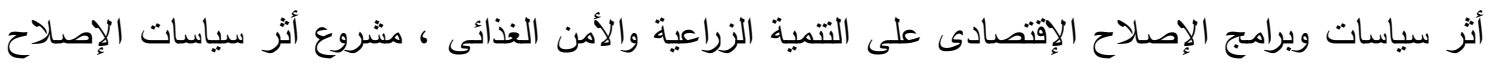

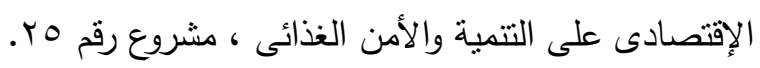

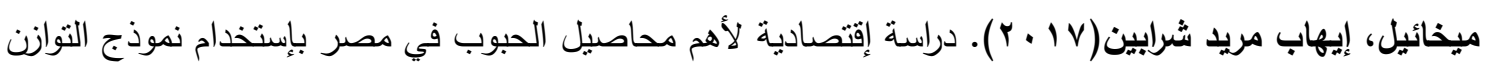

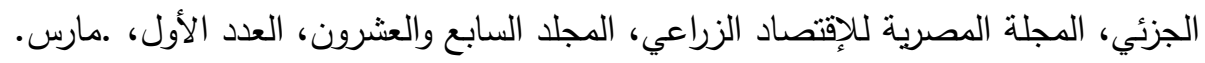

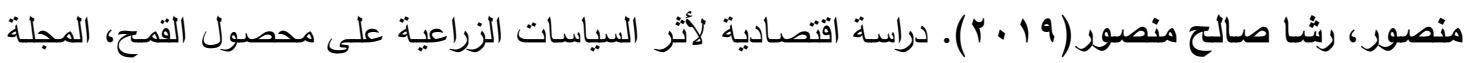

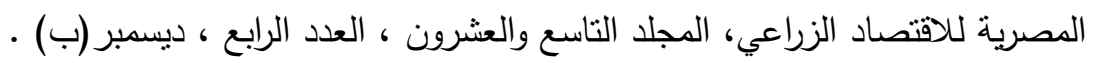
وزارة الزراعة وإستصلاح الأراضى ، الإدارة المركزية للاقتصاد الزراعى ، نثرة الإحصاءات العات الزراعية، أعداد متفرقة.

\title{
Summary
}

\section{Impact of Agricultural Policies on the Soybean in Egypt}

\author{
Manal Mashhour Elsayed \\ Researcher - Desert Research Institute
}

ABSTRACT : The research deals with measuring the impact of agricultural policies for the Soybean crop in Egypt during the period (2000-2018), through study of production, consumption, imports, prices of Soybean, wholesale and retail, measurement of policy matrix analysis, calculation of nominal protection factors for production, nominal protection of input, cost of domestic resources, proportion of government subsidies to producers, support cost policy coefficient during the study period. Analysis of the partial equilibrium model of Soyabean , calculation of nominal protection factors, effective, net social returns and loss, on producer and consumer, distributional effects of producers and consumers, 
total government revenues, foreign exchange earnings for the Soyabean during the study period. It also deals with estimating the marketing efficiency, distribution of consumer Egyptian pound for the Soybean during the study period, estimating the consumption demand function, external import function of Soybean, forecasting the gap of Soybean until 2025, through the four standard models: Increase in demand, straight line model of trend equations, Braun single-parameter model for the double-sided exponential smoothing, Holt double-sided model for the double-sided exponential smoothing.

In order to identify the impact of agricultural policy on the Soybean , the study period (2000-2018) was divided into two time periods, the first period is in the period before the revolution and exchange rate liberalization policies (20002010), while the second period is in the post-revolution period and exchange rate liberalization policies (2011-2018), while the results of development of prices shows the increasing in the prices of producer, wholesale, consumer of Soybean by about $159.5 \%, 184.6 \%, 246.8 \%$ during the period policies Second about the first period of study.

\section{Research Recommendations:}

1. Encouraging farmers to increase the cultivated area and cultivate highyielding varieties, which leads to increase the production of Soybean, where showed a decrease of the self-sufficiency rate about $5.9 \%$ from the first period during the study period.

2. Setting policies aimed at rationalizing domestic consumption of soybean and limiting the import of soybean, as the results of forecasting showed the quantities of soybean production and consumption until 2025, that a slight increase in soybean production is expected to reach about $15.1 \%$, while an increase is expected Significant increase in soybean consumption amounted to about $168.5 \%$ from 2017 according to the Braun Model of single parameter for double exponential smoothing.

3. Taking into account the social dimension, the negative effects of agricultural policies, where it was found that these policies have a positive impact on a Soybean, especially on the production, consumption side, total social returns, distributional effects of producers and foreign exchange earnings, while the implementation of these policies have a negative impact on the distributional effects of Soyabean consumers and government revenues during the two study periods.

\section{Key Words:}

Production and Consumption Soybean Crop - Policy Matrix Analysis - Partial Equilibrium Model - Forecasting Models. 
